San Jose State University

SJSU ScholarWorks

Master's Theses

Master's Theses and Graduate Research

Spring 2019

\title{
The Effect of Porosity on Mechanical Properties of Fused Deposition Manufactured Polymers and Composites
}

Eric Heartly Anderson

San Jose State University

Follow this and additional works at: https://scholarworks.sjsu.edu/etd_theses

\section{Recommended Citation}

Anderson, Eric Heartly, "The Effect of Porosity on Mechanical Properties of Fused Deposition

Manufactured Polymers and Composites" (2019). Master's Theses. 4992.

DOI: https://doi.org/10.31979/etd.rkaj-q4tv

https://scholarworks.sjsu.edu/etd_theses/4992

This Thesis is brought to you for free and open access by the Master's Theses and Graduate Research at SJSU ScholarWorks. It has been accepted for inclusion in Master's Theses by an authorized administrator of SJSU ScholarWorks. For more information, please contact scholarworks@sjsu.edu. 


\title{
THE EFFECT OF POROSITY ON MECHANICAL PROPERTIES OF FUSED DEPOSITION MANUFACTURED POLYMERS AND COMPOSITES
}

\author{
A Thesis \\ Presented to \\ The Faculty of the Department of Chemical and Materials Engineering \\ San José State University
}

\author{
In Partial Fulfillment \\ of the Requirements for the Degree \\ Master of Science
}

by

Eric H. Anderson

May 2019 
(C) 2019

Eric H. Anderson

ALL RIGHTS RESERVED 
The Designated Thesis Committee Approves the Thesis Titled

THE EFFECT OF POROSITY ON MECHANICAL PROPERTIES OF FUSED DEPOSITION MANUFACTURED POLYMERS AND COMPOSITES

by

Eric H. Anderson

APPROVED FOR THE DEPARTMENT OF CHEMICAL AND MATERIALS ENGINEERING

SAN JOSÉ STATE UNIVERSITY

MAY 2019

Dr. Ozgur Keles Department of Chemical and Material Engineering

Dr. Guna Selvaduray Department of Biomedical Engineering

Dr. Raymond Yee Department of Mechanical Engineering 


\title{
ABSTRACT \\ THE EFFECT OF POROSITY ON MECHANICAL PROPERITES OF FUSED DEPOSITION MANUFACTURED POLYMERS AND COMPOSITES
}

\author{
by Eric H. Anderson
}

Additive manufacturing has seen sustained growth in both consumer and industrial areas. fused deposition manufacturing (FDM), a specific additive manufacturing technology, has seen increased sales in consumer markets. In order to maintain growth, FDM will be increasingly used for load-bearing applications. However, the mechanical reliability of FDM polymers and composites is not well understood. This can be dangerous to property and safety. Presented in this paper are more than 16 distinct populations comprised of at least 23 unique tensile tests, a total of 506 tensile tests. Weibull statistics were used to quantify variance in physical properties of FDMed materials. It is the hope of the author that these data will provide essential information for designers to make parameter selections for safe load-bearing applications of FDM parts. Using the deviations from Weibull, scanning electron microscopy, and micro X-ray CT, the author examined the origins of variations in mechanical properties. A key factor in mechanical reliability comprises variations in the size and shape of inter-bead pores. In the final section, this problem was addressed with a novel vibration assisted FDM (VAFDM) that reduced the porosity by $3 \%$, increased the fracture strength by $12 \%$, and doubled the tensile strength reliability. These findings showed that inter-bead porosity can be significantly reduced by localized extruder vibrations and that reduced inter-bead porosity influences the mechanical properties and variations in those properties. 


\section{ACKNOWLEDGMENTS}

I would like to thank Dr. Ozgur Keles for his guidance, encouragement, and patience during this entire thesis process. I would also like to acknowledge the support of Dr. Guna Selvaduray and Dr. Raymond Yee for sharing their knowledge and expertise. A special thank you to Carl Zeiss X-ray Microscopy Inc. and Jeffery Gelb for their assistance in acquiring $\mathrm{x}$-ray $\mu \mathrm{CT}$ image; as well as the Material Engineering SEM lab at SJSU and Ryan Thompson for their assistance in acquiring SEM fracture surface images. Furthermore, the author would like to thank Briana and Alex Cress for their many sacrifices when resurrecting the 3D printer; as well as Jimmy Huynh's sample testing support and David Loja for sample photographs.

I would also like to thank my family Melissa Loja, Cynthia Anderson and William $(\mathrm{Oz})$ Anderson for instilling the value of science and education from a young age. I am eternally grateful for my family's patience, support, and love. None of this would have been possible without the love and support of my grandparents, Bill and Mugsie Anderson. Finally, I'd like to thank my partner, Briana Squiers, for being the light in my life and giving me the motivation to keep moving forward. 


\section{TABLE OF CONTENTS}

LIST OF TABLES viii

LIST OF FIGURES ………………………………........................................ ix

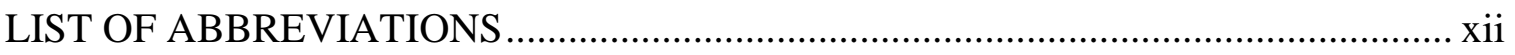

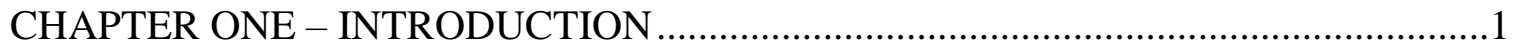

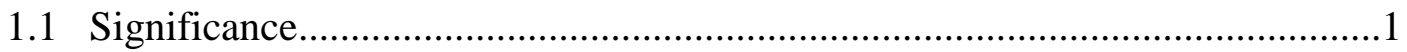

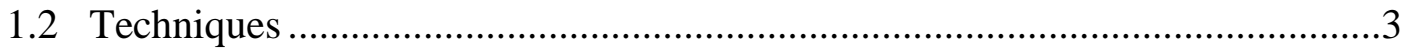

1.3 Motivation ................................................................................................

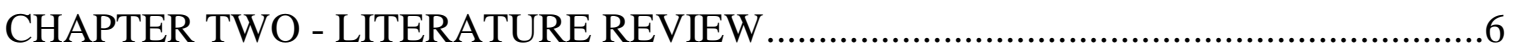

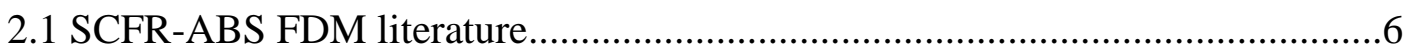

2.1.1 Highly Oriented Carbon Fiber-Polymer Composites AM [65] .......................

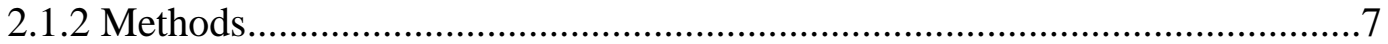

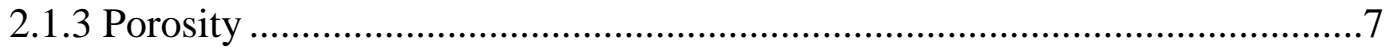

2.1.4 Fiber length distribution.........................................................................

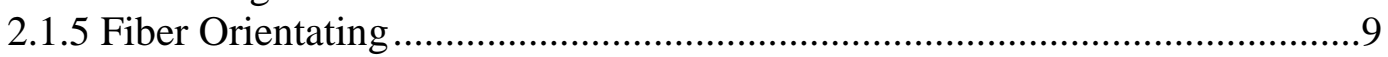

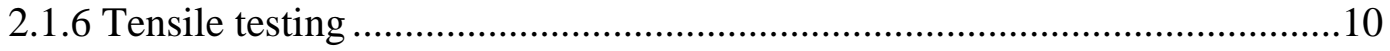

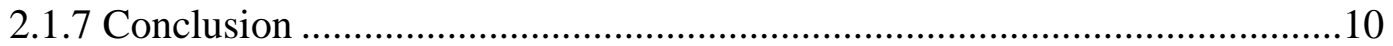

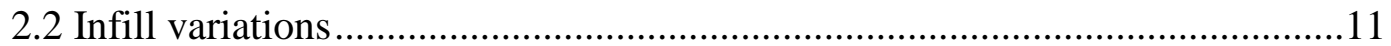

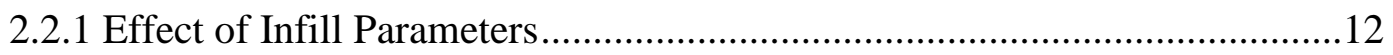

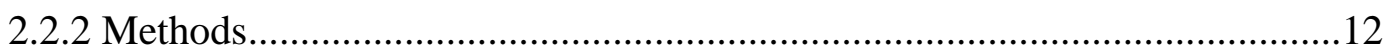

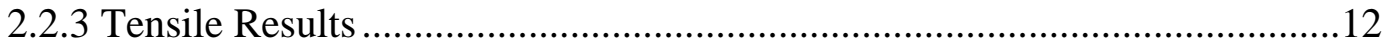

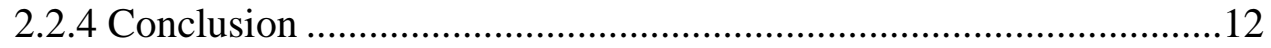

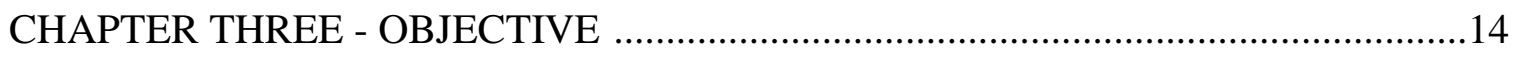

CHAPTER FOUR - MATERIALS AND METHOD ......................................................15

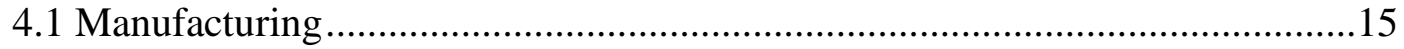

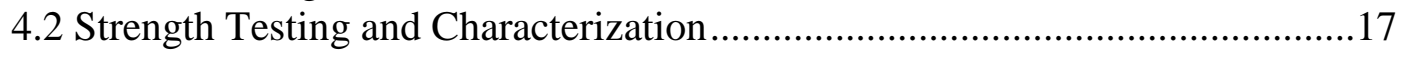

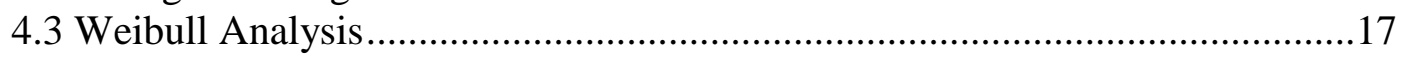

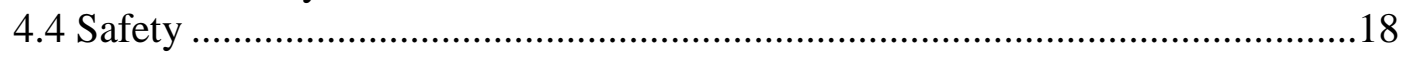

CHAPTER FIVE - STOCHASTIC FRACTURE OF ADD. MAN. POROUS ABS .......20

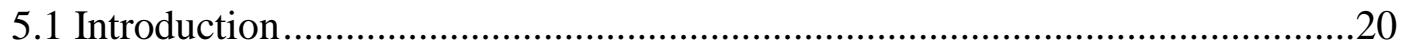

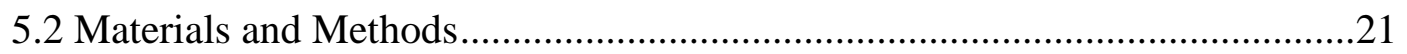

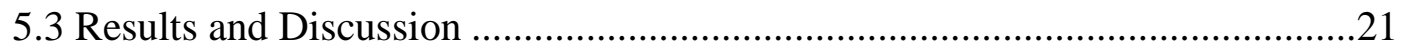

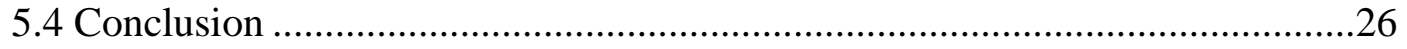


CHAPTER SIX - SHORT CARBON FIBER REINFORCED ABS ………………......28

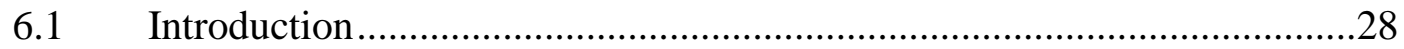

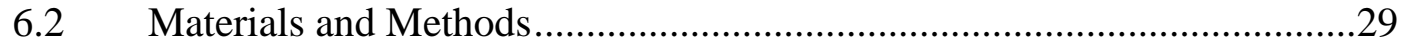

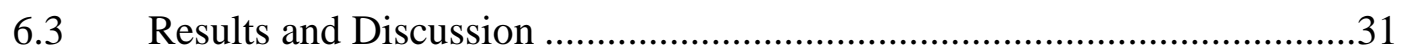

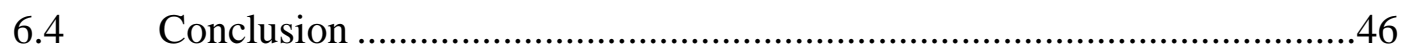

CHAPTER SEVEN - VIBRATED ASSITED FUSED DEPOSITION MODELING .....48

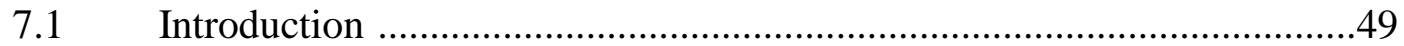

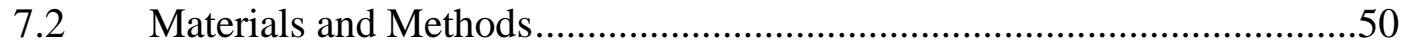

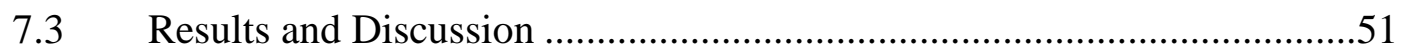

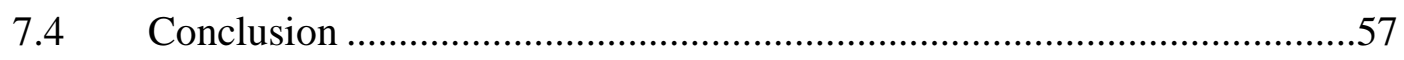

CHAPTER EIGHT - CONCLUSION AND FUTURE WORK …………………….....58

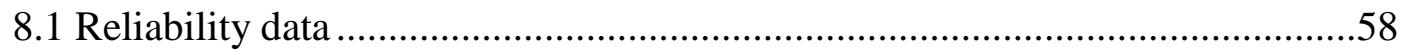

8.2 Investigating the causes of high variance …………...................................59

8.3 Addressing identified causes of mechanical variability.....................................60

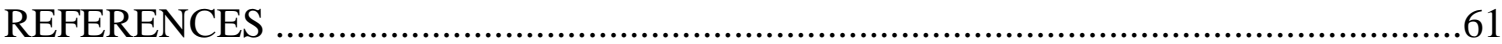




\section{LIST OF TABLES}

Table 1. Slicing Parameters Used to Create G-code .......................................... 16

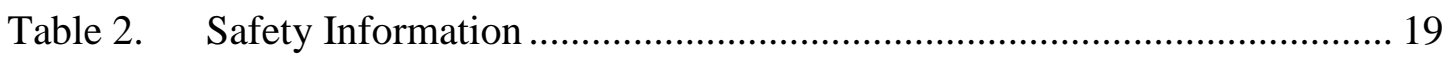

Table 3. Summary of Results from FDMed ABS Study ................................... 25

Table 4. Summary of Results from FDMed SCFR-ABS Study .......................... 35

Table 5. Porosity of Nominally Dense FDMed Material.................................... 59 


\section{LIST OF FIGURES}

Figure 1. Depicts the relationship of carbon fiber on inner-bead and inter-bead formation as well as the specific strength and modulus. Adopted from H.L. Tekinalp et. al. [19].

Figure 2. FDMed tensile test specimens at $20 \%$ (green), $40 \%$ (purple), $60 \%$ (orange), $80 \%$ (blue), and $100 \%$ (red) infill. The point of fracture for each test is marked with an $\mathrm{x}$. A) A single stress-strain plot is shown for each infill percentage, showing characteristic stress-strain behavior. Dips near the $4 \%$ strain are a pause in the test for the removal of the extensometer. B) Density vs. tensile strength of each infill percentage. The black dashed line is a linear fit of the $20 \%, 40 \%$, $60 \%$, and $80 \%$ infill data points, with an equation of $\mathrm{y}=28.11 \mathrm{x}-2.64$, $\mathrm{R}^{2}=.94$

Figure 3. Fracture surface of $100 \%$ infill (left) and $40 \%$ infill (right) by SEM. For two beads, the fracture surface is highlighted in blue, with the remainder of the bead highlighted in red.

Figure 4. Weibull distribution of $20 \%$ (green circle), $40 \%$ (purple $x$ ), $60 \%$ (orange diamond), $80 \%$ (blue + ), and $100 \%$ (red circle) infill percentages. A) Fracture stress, B) tensile strength, C) strain at break, and D) strain at tensile strength are shown.

Figure 5. A visualization of the G-code for the $20 \%$ infill pattern. Areas where the infill does not run parallel with the parameter is highlighted in red. b) A side profile of a broken $20 \%$ infill tensile test coupon. Periodic crazing can be seen along the side of the sample. c) An only-20\%-infill specimen was printed and tensile tested. Crazing is shown in the portion where the infill does not run parallel with the perimeter.

Figure 6. Photographs of internal structure of: a) $20 \%$; b) $80 \%$; c) a representational subsection of the $80 \%$ microstructure; d) simulated $80 \%$ infill structure. Adopted from O. Keles et. al. [37]. 
Figure 7. X-ray computed tomography of a) $100 \%$ infill of FDMed SCFR ABS (inter-bead pores are highlighted in red); b) $100 \%$ infill showing inner-bead pores and inter-bead pores highlighted in red; c) images showing a porous interface between carbon fibers and ABS matrix; d) image of SCFR-ABS as feedstock as-received; d1) crosssection plane of the filament, showing a porous core; d2) images of pores at the carbon-fiber ABS interface in the as-received feedstock; e) extruded filament into air (gray denotes the ABS matrix, red the fibers, and green the pores); f) extruded bead onto a heated bed. Adopted from O. Keles et. al. [37].

Figure 8. Effect of porosity on the average fracture strength of FDMed SCFRABS. The symbol $\Delta$ represents $M 1$, and $\boldsymbol{\Delta}$ represents $M 2$. The symbol $\nabla$ represents $\mathrm{M} 2$ with 0 o bead orientation. The dotted trendline represents a fit of the form $\sigma_{o} \operatorname{Exp}[-b P]\left(\sigma_{0}=\right.$ $30 M P a, b=0.02)$ with an $\mathrm{R} 2=0.99$. Error bars represent one standard deviation. Adopted from O. Keles et. al. [37]. 36

Figure 9. SEM micrographs of the fracture surface of the nominally dense $10 \%$ infill, including photos of a) inter-bead porosity; b) fiber pores; and c) inner-bead porosity. Scale bars correspond to $1 \mathrm{~mm}, 200$ $\mu \mathrm{m}$ and c) $20 \mu \mathrm{m}$. Adopted from O. Keles et. al. [37]. 36

Figure 10. Fiber-length measurements after filament was dissolved in reagent grade acetone (a) and raw filament (c). Extruded filament (b and d). Adopted from O. Keles et. al. [37].

Figure 11. Weibull distribution plot of a) fracture strength; b) tensile strength; c) nominal strain at break; d) strain at tensile strength for FDMed SCFR-ABS. $\mathrm{M} 1 \mathrm{P}=53$ vol. $\% \Delta, \mathrm{P}=41$ vol. $\% \times, \mathrm{P}=34$ vol. $\% \bigcirc$, $\mathrm{P}=25$ vol. $\% \nabla, \mathrm{P}=15$ vol. $\% \diamond$, for $\mathrm{M} 2 \mathrm{P}=13$ vol. $\% \square$, and $\mathrm{P}=23$ vol. $\%+$. Adopted from O. Keles et. al. [37]

Figure 12. Effect of porosity on the Weibull modulus FDMed-SCFR composites; $\Delta$ is for $\mathrm{M} 1, \boldsymbol{\Delta}$ is for material 2 at $100 \%$ infill, and $\boldsymbol{\nabla}$ is for $\mathrm{M} 2$ at $100 \%$ infill in $0^{\circ}$ raster orientation. Error bars correspond to a $90 \%$ confidence interval. Yellow represents moduli of FDMed ABS built in different orientations [18]. Gray represents experimental moduli of various porous ceramics [72]. Blue represents simulated modulus of brittle porous materials [72]. Adopted from O. Keles et. al. [37]. 
Figure 13. Weibull distribution for fracture stress of the extruded filament $(\bigcirc)$, M1 filament $(x)$, and M2 filament $(\diamond)$ Adopted from O. Keles et. al. [37].

Figure 14. a) Schematic of the relative positions of the vibrational motor, extrusion head, and cooling fan, respectively; b) Depiction of the inter-bead porosity generated by the standard fused deposition modeled method; c) Depiction of the inter-bead pore generation from vibrational fused deposition modeled. Adopted from O. Keles et. al. [38]

Figure 15. Linearized Weibull distribution for non-vibrated (blue circle) and vibrated (red x) FDMed SCFR-ABS. $m_{v}, \sigma_{0, v}, m_{n v}$, and $\sigma_{0, n v}$ are vibrated Weibull modulus, vibrated characteristic value, nonvibrated modulus, and non-vibrated characteristic value. a) Fracture stress; b) tensile strength; c) nominal strain at break; d) strain at tensile strength Adopted from O. Keles et. al. [38].

Figure 16. Stress-strain curves of the highest fracture stress of the vibrated and non-vibrated populations. Adopted from O. Keles et. al. [38] 54

Figure 17. Photographs of the surface finish of the vibrated and non-vibrated tensile-test specimens. Adopted from O. Keles et. al. [38]. 


\title{
LIST OF ABBREVIATIONS
}

\author{
AM - Additive Manufacturing \\ AMed - Additively Manufactured \\ FDM - Fused Deposition Modeling \\ FDMed - Fused Deposition Manufactured \\ $\mu \mathrm{CT}$ - Microcomputed Tomography \\ SEM - Scanning Electron Microscopy \\ ABS - Acrylonitrile Butadiene Styrene \\ SCFR - Short Carbon Fiber Reinforced \\ $\mathrm{CM}$ - Compression Molded \\ VA-FDM - Vibrated Assisted Fused Deposition Manufacturing \\ TS - Tensile Strength \\ $\sigma_{f}-$ Stress at Fracture \\ $m$ - Weibull Modulus \\ $\epsilon_{f}-$ Strain at Fracture \\ $\epsilon_{T S}-$ Strain at Tensile Strength
}




\section{CHAPTER ONE \\ INTRODUCTION}

\subsection{Significance}

Additive manufacturing (AM) is seeing increasing use for applications that require metal, polymer, ceramic, and composite materials [1]. AM provides unprecedented design flexibility, outsource manufacturing, automation, material usage efficiency, and on-demand production, which is reflected in the AM industry's $31.5 \%$ annual growth rate over the last three years and overall growth of $26.2 \%$ in the last $27[2,3]$. AM has seen growth in many industries, including aerospace [4], medical [5], defense [6], automotive [7], consumer-grade manufacturing [8], dentistry [9], and open-source design [10]. In this context, AM can extend distributed manufacturing - that is, to produce parts locally [3, 11]. AM can be competitive for productions up to 10,000 parts [12]. Accordingly, the variations in mechanical properties must be known to ensure consistent production of parts. However, mechanical strength and reliability of additively manufactured (AMed) composites are unclear. Specifically, stochastic fracture of AMed materials have not been thoroughly investigated. One of the main reasons is the large number of specimens required to obtain statistically significant fracture data.

The major technologies in AM are as follows: selective laser sintering, stereolithographic, polyjet, electronic beam melting, and fused deposition modeling (FDM) [1]. Among these technologies, FDM can use relatively inexpensive materials, making it accessible to industrial and consumer-level production. Commonly used polymers in FDM are acrylonitrile butadiene styrene (ABS), polylactic acid, and acrylate resin and nylon powder [13]. These polymers are affordable and contribute to FDM's 
exponential increase in consumer-grade sales [2]. With 140,000 units sold in 2014 and 250,000 units sold in 2015, FDM has become the most used AM technology [2]. Consumer demand shifts FDM printer usage from modeling and prototyping to loadbearing parts [1]. Load-bearing fused deposition manufactured (FDMed) prosthetics [14], medical implants [15], automotive parts [16], and casting manufacturing [17] have been reported.

One advantage of additive manufacturing over traditional subtractive methods is the ability to control internal structure. This flexible production enables spatial control of pores, which can be used to tailor mechanical behavior and reduce weight. Generally, FDMed materials are produced with a fixed porosity described by the infill parameter. However, the direct relationship between porosity and mechanical reliability for FDMed parts is not well understood.

Recent work has shown that FDM produces parts with lower mechanical reliability than their subtractive manufactured counterparts [18]. These part-to-part variations can pose harm to consumers using FDM for load-bearing applications. Reliability is an important design consideration for any load-bearing application but specifically for larger-scale manufacturing.

Porosity can be advantageous for decreasing the weight and material usage of an FDMed part. Tekinalp et al. described two characteristic pores caused by the FDM method: inner-bead and inter-bead pores [19]. Beads, also referred to as "roads," are the lines of extruded plastic of which FDM parts are composed. Inner-bead pores are described as the pores contained within the bead. Inter-bead pores are described as the 
pores that exist between beads. Even at $100 \%$ infill (i.e., nominally dense material), Many FDM studies found significant inter-bead porosity [19]. The rounded beads cannot fill the entire space completely. Inter-bead porosity was reported to decrease with carbon fiber percentage due to higher thermal conductivity and die swell. Inner-bead porosity, however, showed an increase caused by poor fiber-matrix adhesion in FDMed shortcarbon-fiber-reinforced polymers [19].

Finding the effects of infill parameter on various mechanical properties FDMed ABS has been an area of interest [20-24]. Fernandez-Vicente et al. compared the tensile strength of open-source FDMed ABS with three different infill patterns [24]. The tensile strength was found to be 16,20 , and $36 \mathrm{MPa}$, for $20 \%, 50 \%$, and $100 \%$ rectilinear infills, respectively. With five replicates in each infill, the specimens were modeled with a quadratic relationship $\sigma_{p} \cong 15 * 10^{-3} M P a * x^{2}$, where $\sigma_{p}$ is the tensile strength and $\mathrm{x}$ is the infill density.

\subsection{Techniques}

Analyzing mechanical reliability using Weibull statistics [17] is a common practice in ceramic AM literature [25-28] due to high variability in fracture stress. Although Weibull statistics are not commonly used for polymers, the author recently showed that the variation in FDMed ABS-dense materials can be as high as ceramics [29]. There are currently no reports on the mechanical reliability of AMed short carbon-fiber reinforced acrylonitrile butadiene styrene (SCFR-ABS) composites. In the present study, the author investigated the effect of porosity on the variations in fracture stress (i.e., the effect of porosity on a Weibull modulus). 
$\mathrm{X}$-ray microcomputed tomography (X-ray $\mu C T)$ has been shown to give qualitative results for pores' shape and morphology, a distinct advantage over scanning electron microscopy (SEM), Mercury porosimetery, gas pycnometry, and other imaging techniques [30]. In FDM, X-ray $\mu C T$ has proven feasible for characterizing the structural features of the roads and the length, width, and orientation of composite fibers [31-34]. The microstructural features and carbon-fiber length, width, and orientation has been shown to be the major contributor in mechanical strength and can be quantitatively determined using micro $\mathrm{X}$-ray $\mu C T$ techniques[35, 36].

\subsection{Motivation}

This thesis aims to give an overview of the author's work regarding the stochastic fracture of FDMed ABS and SCFR-ABS. This topic is broken down into three experiments: stochastic fracture of additively manufactured porous ABS (chapter five), stochastic fracture of additively manufactured porous composites (chapter six) [37], and mechanical reliability of short carbon-fiber reinforced ABS produced via vibrationassisted fused deposition modeling (chapter seven) [38]. Chapters six and seven are summaries of published papers [37, 38], of which the author is not the first author. This paper will focus specifically on what the author has contributed to the work while still discussing the findings in meaningful ways.

The results and conclusions reached in this paper can be summarized into three categories: presenting data, investigating causes in the variance of mechanical properties, and addressing the proposed cause. The subsequent paragraphs will suggest to the motivation behind each of these categories. 
As mentioned in chapter 1.1, a large data set on the mechanical properties of FDMed ABS and SCFR-ABS is missing literature. This data set gives insight into the degree of variation that can be expected from consumer-grade FDM. It is the hope of this author that these data can be leveraged by slicing software to make parameter selections with the designers' desired load and reliability. In this way, load-bearing applications for FDM parts can be produced safely with significant material knowledge needed by the user. It is the author's belief that this will produce safer parts, mitigate unnecessary material usage, and expand the efficacy of FDM parts.

This paper discusses potential causes of mechanical variation. These conclusions are made after examining Weibull distribution, fractography, and micro X-ray CT data. This discussion alludes to potential causes that should be further investigated. The claims made should not be taken as assertions but as areas of interest. It is the hope of the author that the factors outlined in this paper will lead to further improvements in mechanical reliability.

Finally, this paper will conclude with an experiment on one of the largest factors believed to contribute to mechanical reliability: variations in inter-bead porosity. The author addresses the variations by introducing localized vibrations on the extruder head. Via SEM, the author qualitatively determines a reduction in inter-bead porosity and observes a $12 \%$ increase in tensile strength (TS) and a $200 \%$ reduction in mechanical variability. In this way, the author demonstrates a novel and inexpensive method of increasing the mechanical properties of FDMed materials. It is hoped that this will increase the efficacy of FDM printing for load-bearing applications. 


\section{CHAPTER TWO \\ LITERATURE REVIEW}

Weibull analysis of varying porosities of FDM SCFR-ABS is novel. It combines the approach, manufacturing, and material of a system never reported on before. The major findings in FDM SCFR-ABS, the effect of infill on mechanical properties, and Weibull statistics are discussed in this section. The author uses these findings as a basis to discuss the effects of porosity on the reliability of FDMed SCFR-ABS.

\subsection{SCFR-ABS FDM Literature}

SCFR-ABS is a desired material for FDM for its improved density, toughness, and mechanical, electrical, and thermal properties [39-41]. Although studied in the extrusion compounding and injection-molding processes [42-44], SCFR-ABS has not been highly studied for FDM. Mechanical properties have been shown to significantly depend on the porosity, fiber-length distribution, and fiber-orientation distribution of the final parts.

Ning et al. correlated carbon-fiber length with higher ultimate tensile stress, which explains major differences between the values of Tekinalp et al. and Ning et al. However, when comparing the $10 \mathrm{wt} . \%$ of Shofner and Ning et al., it is seen that variation in processing can cause significant differences in reported stress for the same carbon-fiber length. Ning et al. and Shofner et al. tested five and six replicates, respectively.

The remainder of this section will focus on the work of Tekinalp et al. due to its focus on the three factors that affect mechanical reliability: fiber length, fiber orientation, and porosity. By changing the infill percentage, the inter-pore percentage (which has been defined in this paper) changes directly. The effects of FDM on fiber length and fiber orientation are also widely discussed in this paper. 


\subsubsection{Highly Oriented Carbon Fiber-Polymer Composites via AM [19]}

In the work of Tekinalp et al. on highly oriented carbon-fiber polymer composites, the microstructural and mechanical properties were compared for FDM and compressionmolded (CM) techniques. The microstructure analysis depicted two pore vacancies for FDM modes that were shown to have dependence on carbon-fiber concentration. The tensile strength and modules showed an increase of $115 \%$ and $700 \%$, respectively. A fiber alignment of $91.5 \%$ was achieved using FDM printing, significantly higher than compression-modeling techniques.

\subsubsection{Methods}

Mixtures of $0 \%, 10 \%, 20 \%, 30 \%$, and $40 \%$ SCFR-ABS were created using a Brabender Intelli-Torque Pliati-Corder prep mixer at $220^{\circ} \mathrm{C}$. A slit-shaped and cylindrical die was used for CM and FDM, respectively. The American Society of Testing Materials (ASTM) D638 dog-bones were created using the FDM printer Soliddoodle 3 (from Solidoodle Co., New York).

\subsubsection{Porosity}

Tekinalp et al. compared the microstructure of raw ABS with that of composite FDMed and found two types of porosity. Inter-bead porosity features triangular pores that are byproducts of FDM printing. When the nozzle prints against a surface, the filament flattens and elongates while the top side cools to form rounded edges before the next layer is deposited. The triangular pores are not expected to have a significant effect on the mechanical properties because the pore channels are aligned with the tensile test direction. It is important to note that in this experiment, the infill angle (hatch angle) of 
the infill roads was set to $0^{\circ}$ for all layers. For nonzero hatch angles, the pore channel is not aligned with the tensile direction and has been shown to produce much weaker specimens [45].

There was a significant reduction in inter-bead porosity with the addition of carbon fibers. Carbon fiber significantly eliminates die-swell and improves the thermal conductivity, causing bead softening and smaller bead size. This reduction is one of the causes for the increase in specific strength and specific modulus, as shown in Figure 1.

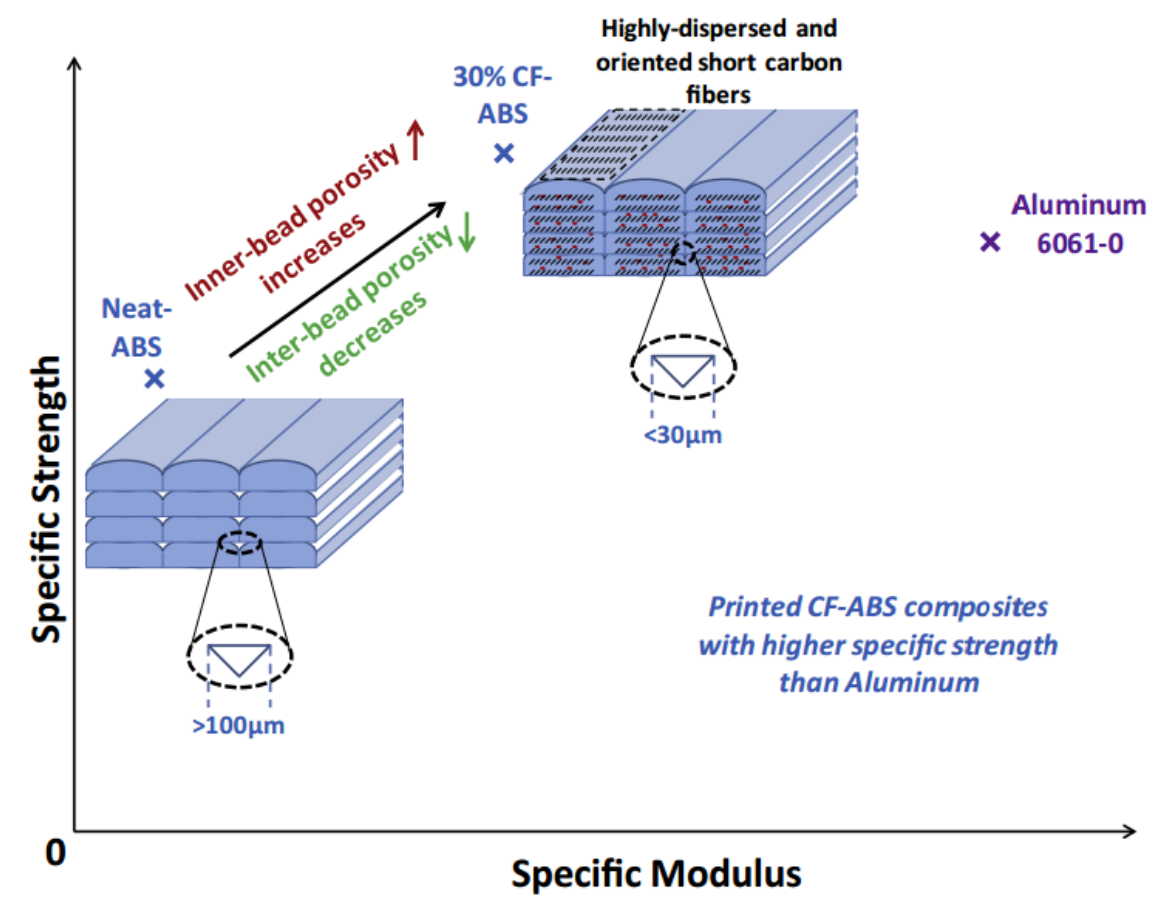

Figure 1. Depicts the relationship of carbon fiber on inner-bead and inter-bead formation as well as the specific strength and modulus. Adopted from H.L. Tekinalp et. al. [19].

Inner-bead pores are caused by increasing fiber ends [19]. SEM shows pore enlargement around the fibers for the FDM but not for the CM samples. This enlargement 
by FDM printing lowered the fiber-matrix interfacial contact area and was expected to reduce strength.

\subsubsection{Fiber-Length Distribution}

To access fiber length, a major contributor to mechanical strength, the ABS in the samples was dissolved with acetone. Micrographs of 1,000 carbon fibers were taken at 20x zoom. Code was then developed to determine the fiber-length distribution.

The fiber-length distribution for CM and FDM both decrease with increasing weight percentages. Even though $3.2 \mathrm{~mm}$-long fibers were used during processing, the average fiber length for both $\mathrm{AM}$ and $\mathrm{CM}$ processes was found to be lower than $0.4 \mathrm{~mm}$. This suggests significant fiber breakage during the processing steps. Previous research has shown that the leading causes of fiber breakage during processing are interactions with the fiber and the instrument surface, resin, and other fibers [19]. As the carbon percentages increase, these fiber interactions cause increased fiber breakage, thus lowering fiber length.

\subsubsection{Fiber Orientating}

To determine fiber orientation, the Bay and Tucker fiber-orientation methodology was used. This method consists of imaging a polished internal surface and using fiber surface morphology to determine second-order fiber orientation.

The results of Bay and Tucker's method was a high fiber orientation in the raster direction for FDM, compared to CM methods. With $90 \%$ of the fiber printing in the raster direction, FDM is a strong manufacturing technique for aligning carbon fibers. In 
this study, the raster direction is the most mechanically favorable orientation because it is in the load-bearing direction.

\subsubsection{Tensile Testing}

As previously mentioned, this study focuses on the fiber length, fiber orientation, and porosity of SCFR-ABS. It has previously been shown that tensile strength increases with fiber length and orientation and decreases with increasing porosity. Despite the voids created by FDM, neat ABS showed higher tensile strength than CM methods. This suggests that the molecular orientation is improved with FDM methods [19]. The tensile strength and modulus showed a general increase in carbon fiber percentage for both FDM and CM methodologies.

At least five specimens were tested in each test case, and standard deviations were calculated. FDM showed a significantly lower standard deviation than CM. This suggests that the FDM method not only increases the orientation of the fibers, but also increases the dispersion of fibers compared to CM. The standard deviation of neat polymers is higher than that of the carbon fiber; this suggests sample-to-sample differences in carbonfiber dispersion.

\subsubsection{Conclusion}

Varying carbon-fiber weight percentages were manufactured using FDM and CM methodologies. The three largest contributors to mechanical strength, fiber length, fiber orientation, and porosity were studied. Fiber length was measured using micrograph techniques and determined similar carbon-fiber-length averages between FDM and CM. In both techniques, significant fiber breakage was observed. Fiber orientation was 
observed using the Bay and Tucker [46] polished-surface 2-D ellipsoid method. A significant increase in the carbon-fiber orientation was observed. No porosity was observed in the CM models, but significant porosity was observed in the FDM samples. The pores that arose from gaps in between pores the were termed "inter-bead pores". The pores within the beads were termed "inner-bead pores". Via SEM, it was determined that the inter-bead pores decreased with carbon-fiber concentration, but the number of innerbead pores increased.

Tensile test methods showed increasing tensile strength and modulus with increasing carbon-fiber weight percentages. Based upon the standard deviations of a five-sample minimum, it was determined that there was better dispersion of the carbon fiber in the FDM methodology. The strength of neat ABS was higher in FDM compared to CM methodologies. This suggests an alignment of the polymer chains in the ABS process as described by Sood et al. [47]. Carbon fibers were seen by SEM to be pulled out of the matrix. This suggests weak interfacial adhesion between the fiber and the matrix. Tekinalp et al. suggested improving the interface between fiber and matrix for the largest improvement in mechanical properties [19].

\subsection{Infill Variations}

Very few papers have been published that examine infill effect on mechanical properties. Baich and Manogharan analyzed print cost and time based on infill percentages using a slicing software that does not allow the fine-tuning of infill percentages. In this study, the focus will be on the paper of Fernandez-Vicente et al. as it 
specifically addresses varying infill and patterns and percentages for RepRap printers. 2.2.1 Effect of Infill Parameters on Tensile Mechanical Behavior in Desktop Printing In the work of Fernandez-Vicente et al. [26], five replicate-FDMed pure ABS samples were tested at infills of $20 \%, 50 \%$, and $100 \%$. The tensile strengths were found to be $15.62,19.58$, and $36.40 \mathrm{MPa}$, for $20 \%, 50 \%$, and $100 \%$ infills, respectively. The specimens were modeled with a quadratic relationship and are shown in Equation 1.

$$
\sigma_{p}=15.2364 \mathrm{MPa}+.002083 * x^{2} \quad \text { Equation } 1
$$

Where $\sigma_{p}$ is the tensile strength, and $\mathrm{x}$ is the infill density.

\subsubsection{Methods}

The three infill patterns studies in this paper are rectilinear, honeycomb, and line, with $20 \%, 50 \%$, and $100 \%$ infill parameters. These patterns were created on the slic $4 \mathrm{r}$ version 1.0 and printed on the RepRap Prusa i3.

\subsubsection{Tensile Results}

The tensile strengths of the rectilinear model were found to be $15.62,19.58$, and 36.40 MPa for the $20 \%, 50 \%$, and $100 \%$ infills, respectively. As expected, the $20 \%$ infill parameter was the weakest out of the three infill patterns; while, the $100 \%$ parameter was found to be the strongest of the three. This is particularly interesting because the $100 \%$ infill parameter was also the lightest of the three specimens. The authors hypothesized that the difference may be related to inter-bead interactions, of which the rectilinear model has the most.

\subsubsection{Conclusion}

The maximum tensile strength found in this paper was a $100 \%$ infill, which shows a 36.4 $\mathrm{MPa}$ - a difference of $1 \%$ of raw ABS material. The difference in elastic modulus 
between the honeycomb and the rectilinear pattern is due to the deposition trajectories and the interlayer bonding zones. Finally, the relationship between infill density and tensile strength can be fitted in a squared-X model. 


\section{CHAPTER THREE \\ OBJECTIVE}

This paper covers three topics on which the author has worked extensively: stochastic fracture of additively manufactured porous ABS (chapter five); stochastic fracture of additively manufactured porous composites (chapter six) [37]; and mechanical reliability of short carbon-fiber reinforced ABS produced via vibration-assisted fused deposition modeling (chapter seven) [38]. The broad goal of these three papers is to understand the variability of FDMed materials. This goal can be divided into three components: providing a data set that is not present in literature, listing novel suggestions on improving reliability, and experimentally improving reliability based on suggestions. Experiments from chapters five and six will provide data sets and suggestions for improving reliability. In chapter seven, the author shows improvement in mechanical reliability by addressing one of the suggested sources. 


\section{CHAPTER FOUR MATERIALS AND METHODS}

In this chapter, the necessary materials and methods are described. This section will cover all testing that is similar between the ABS, SCFR-ABS, and VA SCFR-ABS experiments. Experimental methodologies specific to the individual experiments will be located in the papers' respective chapters (ABS — chapter 5.2; SCFR-ABS—chapter 6.2; VA-FDM-chapter 7.2).

The Instron 4204 Universal Tester was used to perform and record tensile test data. The FEI Quanta 200 took the SEM images. The Prusa i3 3-D printer was the open-source FDM printer used. The Instron 4204 Universal Tester and FEI Quanta are available to students in the material engineering department. The Prusa i3 3-D printer is the property of Dr. Ozgur Keles's research lab, to which the author belongs.

\subsection{Manufacturing}

The tensile test specimen was modeled from a modified ASTM D638 Type 1 standard using SolidWorks 2016 computer-aided design software. The modification is necessary because the curvature of the dog-bone sample causes defects and fractures in invalid test areas [48]. The curvature was removed to form a rectangular box with a length of $165 \mathrm{~mm}$, a width of $13 \mathrm{~mm}$, and a height of $3.6 \mathrm{~mm}$.

A stereolithographic file (STL) was then created using SolidWorks with the maximum polygon count allotted. Ten identical models were made and oriented using the open-source software suit Repetier-Host (version 1.6.2). The G-code, numerical control programming language, for the 10 models was created using Repetier-Host's built-in 
plug-in, Slic3r. The printing parameters used in generating the G-code are described in Table 1.

Table 1 Slicing Parameters Used to Create G-code.

\begin{tabular}{lc}
\hline Print Parameters & Value \\
\hline Cross head speed (mm/min) & 7800 \\
Raster Orientation (Deg) & $45 /-45$ \\
Perimeter Overlap (\% of extruded perimeter width) & 15 \\
Bed Temperature (Celsius) & 125 \\
Nozzle Temperature (Celsius) & 235 \\
Layer Thickness & $.3 \mathrm{~mm}$ \\
Number of parameters & 1 \\
X-Y deposition speed (mm/min) & 4800 \\
Fill density & $20,40,60,80 \mathrm{and} 100 \%$ \\
Filament diameter & $1.75 \mathrm{~mm}$ \\
Nozzle diameter & $.6 \mathrm{~mm}$ \\
\hline
\end{tabular}

Five variations of these files were created with varying infill percentages: $20 \%, 40$ $\%, 60 \%, 80 \%$, and $100 \%$. The top and bottom two layers were set to solid infill to ensure level grip area and isotropic grip stress distribution. Four batches of 10 were printed for each infill percentage to ensure 30 samples for the Weibull analysis.

Adhesion is a common difficulty in FDM. As the manufacturing progresses, thermal contraction causes the part to delaminate. To address this, a thin layer of ABS dissolved in commercial grade acetone was used. A thin layer was dispersed with a painter's brush; this layer needed to be reapplied after every batch. Batches of 10 samples took two to five hours, depending on infill, and were often left to run unattended. Any unexpected 
variations occurring during unattended printing are characteristic of real processing conditions.

\subsection{Strength Testing and Characterization}

Tensile tests were conducted on printed specimens using am Instron 4204 Universal Tester with Bluehill 3 data-analysis software at a strain rate of $1 \mathrm{~mm} / \mathrm{min}$. A static axial clip-on extensometer provided gauge strain. Length, width, thickness, and weight measurements were made on all samples' density, strain, and geometric changes from the printer.

An FEI Quanta 200 scanning electron microscope was used to measure fracture surface. Gold/palladium alloy sputtering was required to image the fracture surface of ABS samples but was not needed for carbon-fiber samples.

\subsection{Weibull Analysis}

Mechanical reliability, or variations in fracture strength, is commonly quantified by the two-parameter Weibull distribution [49].

$$
F(\sigma, V)=1-\exp \left[-\frac{V}{V_{0}}\left(\frac{\sigma}{\sigma_{0}}\right)^{m}\right]
$$

Where the probability of failure $(F)$ is related to the volume $(V)$ and applied stress $(\sigma)$. The Weibull modulus $(m)$ is the shape parameter. Higher $m$ results in less variation in strength. The scale parameter $\left(\sigma_{0}\right)$ or characteristic strength corresponds to the failure probability of $63 \%$. The volumes of test specimens in each batch, and from batch to batch, do not differ significantly from the normalized volume $\left(V_{0}\right)$; thus, the author sets $\frac{V}{V_{o}}=1$. Performing a two-parameter Weibull analysis on tensile test data gives the 
probability of failure at a given stress or strain value - essential for designing the loadbearing parts safely.

Apart from the previous work, the only paper to analyze additively manufactured material using Weibull statistics is that of Meininger et al. [50]. This 2016 work uses a three-dimensional powder printing technique to create strontium substituted magnesium phosphate scaffolds for the purpose of in vitro bone cement. Meininger et al. calculated the Weibull moduli for varying sintered and hardened methods for three different magnesium strontium phosphate mixtures. They also showed that the $M g_{2} \mathrm{Sr}_{1}\left(\mathrm{PO}_{4}\right)_{2}$ scaffolds had the highest Weibull modulus of $m_{c s}=8.8$ and therefore were the most reliable under compression [50].

\subsection{Safety}

The AM material SCFR-ABS is the main material used in this experiment. The print head is operated $235^{\circ} \mathrm{C}$ and can cause burns with direct contact. To relieve burns, it is advised to soak under water for 15 minutes. If skin irritation persists, one is instructed to call a doctor. It does not self-ignite and decomposes at $508^{\circ} \mathrm{C}$, so it is important to check to see that the printer is working at measured temperatures. Inhalation of ABS particles can be harmful to health, so it is advised to avoid sanding or creating fine particles. If exposed, one should move to fresh air and consult a physician.

Acetone is used to dissolve the SCFR-ABS, which is then used as an adhesive used during printing. Acetone is an irritant; for skin exposure the area should be flushed with lukewarm, gently flowing water for 5 minutes, and 15 to 20 minutes for eye exposure. If 
skin contact is serious, one should use disinfectant soap and cover contaminated skin with an antibacterial cream. In all scenarios, medical attention is needed.

Acetone is flammable with an auto-ignition of $465^{\circ} \mathrm{C}$ and a flash point of $-20^{\circ}$ and $-4^{\circ}$ C for a closed and open cup, respectively. Chemicals should be stored in a fire cabinet. To combat fire, one should use dry chemical powder, alcohol resistant foam, water spray, or fog. A summary of the safety information regarding SCFR-ABS and acetone is shown in Table 2.

Table 2 Safety Information

\begin{tabular}{lccll|} 
Chemical & Health & Flammability & $\begin{array}{l}\text { Personal } \\
\text { Protective } \\
\text { Equipment }\end{array}$ & Other \\
\hline $\begin{array}{l}\text { SCFR- } \\
\text { ABS }\end{array}$ & 0 & 1 & 0 & Eye protection \\
\hline & 1 & 3 & 0 & $\begin{array}{l}\text { Gloves, lab coat, } \\
\text { vapor respirator }\end{array}$ \\
Acetone & 1 & 3 &
\end{tabular}




\section{CHAPTER FIVE \\ STOCHASTIC FRACTURE OF ADDITIVELY MANUFACTURED POROUS ABS}

In this chapter, the author measures the effect of porosity on the mechanical properties of FDMed ABS. The variance in mechanical properties is described using Weibull statistics, as related in chapter four. In this way, the author can imply the root causes' of variation and mechanical properties. The following section will present the mechanical properties of five different populations of porosities. To generate samples of varying porosities, the infill percentages of $20 \%, 40 \%, 60 \%, 80 \%$, and $100 \%$ were used. The infill parameter changes the degree of inter-bead porosity. In this way, researchers can directly see the effect of inter-bead porosity on mechanical properties and mechanical reliability.

In this chapter, more than 300 tensile tests will be presented. This large data set can be leveraged by slicing software to make informed parameter selections. Ideally, a user would simply need to specify a tensile load and desired reliability, and the software would make the appropriate selection.

\subsection{Introduction}

With more than 300 samples printed and tested, this study is the largest of its kind. Reliability will be determined for five infill percentages: $20 \%, 40 \%, 60 \%, 80 \%$, and $100 \%$. It will provide programmers, designers, and consumers with information they can use to design load-bearing parts safely. The effect of inter-bead porosity on reliability and other mechanical properties will be examined. 


\subsection{Materials and Method}

Octave Inc. acrylonitrile-butadiene-styrene polymer filament was used on a RoaddogLabs Baja i3 rework to print all tensile test specimens. Due to the difficulties of breaking at the tensile test grip, the contours of an ASTM D638 were removed to form a rectangular box of the following dimensions: 165 x 13 x $3.6 \mathrm{~mm}$. The open software Slic3r (version 1.2.9, Slic3r (n.d.)), was used to create the toolpath of the FDM. Each tensile test specimen consisted of 12 layers. To minimize the effect of surface defects on the mechanical properties of the specimen, the top two and bottom two were kept at 100 $\%$ infill, while layers 3-10 had variable infill percentages at $20 \%, 40 \%, 60 \%$, and 100 $\%$. A rectilinear fill pattern was used with a single contour. A $0.4 \mathrm{~mm}$ nozzle extruded filament at $235^{\circ} \mathrm{C}$ onto a $125^{\circ} \mathrm{C}$ bed.

\subsection{Results and Discussion}

The consolidation of fracture points for all tensile tests is plotted in Figure 2. As expected, there is a clear separation in the fracture stress and Young's modulus of the different infill percentages. Between $20 \%, 40 \%, 60 \%$, and $80 \%$ infill, average tensile strength increases at a rate of $17 \%$. However, between $80 \%$ and $100 \%$, there is a $30 \%$ increase in tensile strength. This is exemplified in Figure $2 \mathrm{~b}$, with the $100 \%$ infill red data points significantly out of the range of the linear fit of infill percentages $20 \%, 40 \%$, $60 \%$, and $80 \%$. This implies that there is a further strengthening in the $100 \%$ infill parameter that cannot be explained by the increase in density alone. 
A)

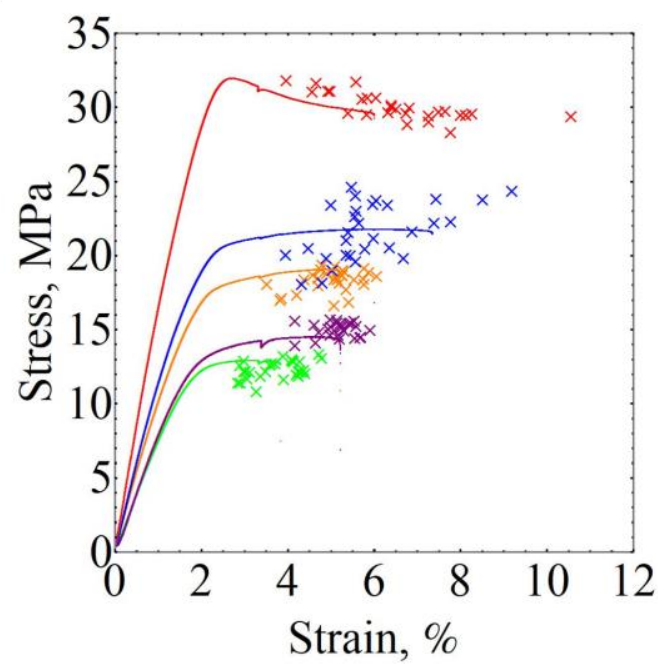

B)

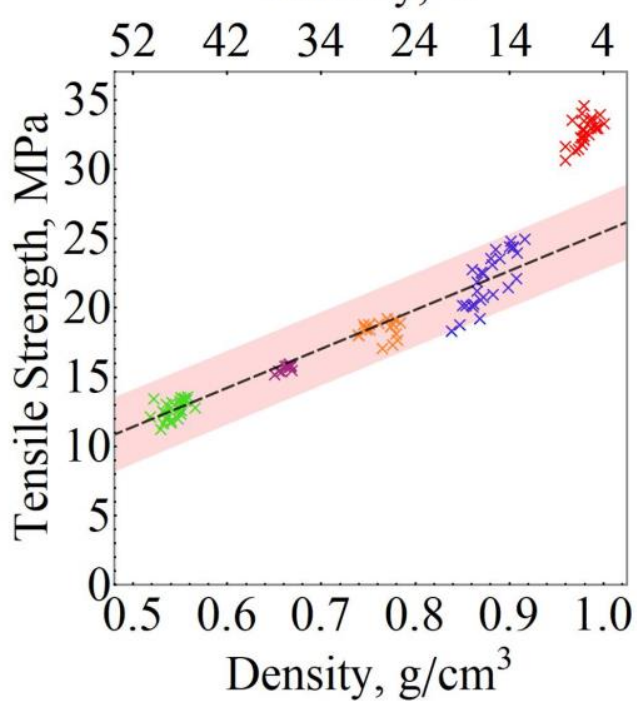

Figure 2. FDMed tensile test specimens at $20 \%$ (green), $40 \%$ (purple), $60 \%$ (orange), $80 \%$ (blue), and $100 \%$ (red) infill. The point of fracture for each test is marked with an $x$. A) A single stress-strain plot is shown for each infill percentage, showing characteristic stress-strain behavior. Dips near the $4 \%$ strain are a pause in the test for the removal of the extensometer. B) Density vs. tensile strength of each infill percentage. The black dashed line is a linear fit of the $20 \%, 40 \%, 60 \%$, and $80 \%$ infill data points, with an equation of $\mathrm{y}=28.11 \mathrm{x}-2.64, \mathrm{R}^{2}=.94$.

One possible explanation for this increase in tensile strength is the physical touching from bead to bead. As hot beads are extruded next to each other, the beads merge into a homogeneous material. This can be seen in Figure 3, comparing the fracture surfaces of the $100 \%$ and $40 \%$ infills. The bead to bead interface in the $100 \%$ infill increases the fracture surface for an individual bead. The crack must propagate along the length of the bead as well as perpendicular to the bead. This increased fracture area leads to increased toughening as the crack travels longer under similar stress. 

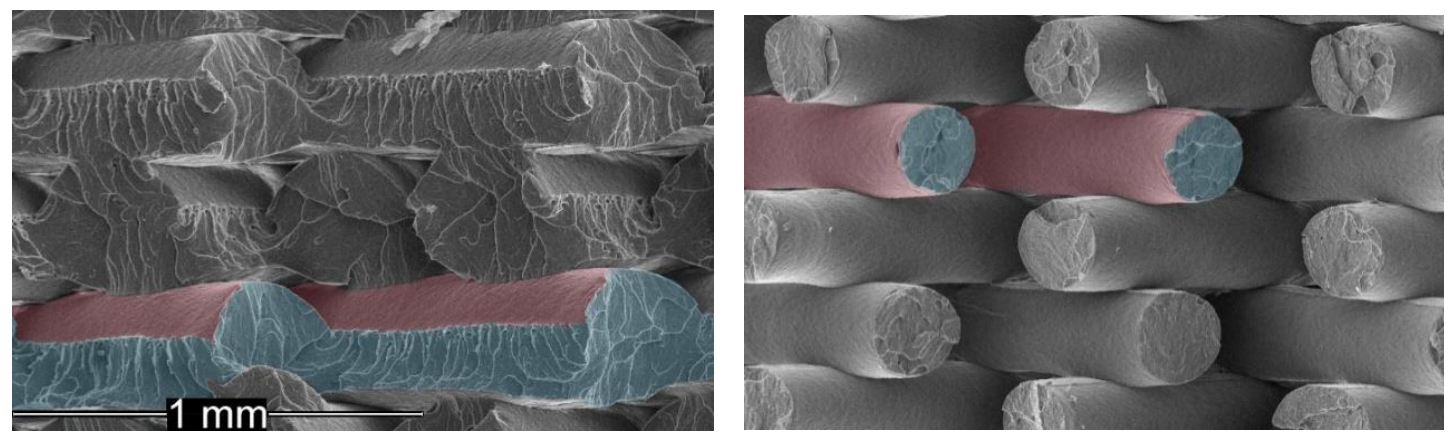

Figure 3. Fracture surface of $100 \%$ infill (left) and $40 \%$ infill (right) by SEM. For two beads, the fracture surface is highlighted in blue, with the remainder of the bead highlighted in red.

Looking at the distribution of fracture points in Figure 2, $80 \%$ (blue) shows a much higher distribution in fracture stress than other infill percentages. This can be seen in the linearized Weibull plot shown in Figure 4. The slope of the line, or Weibull parameter $m$, is highest for $80 \%$ infill. According to these data, $80 \%$ infill has the lowest reliability of all the infills. The reliability of the $80 \%$ infill seems to be correlated to the large distribution of density, as shown in Figure $2 b$. 

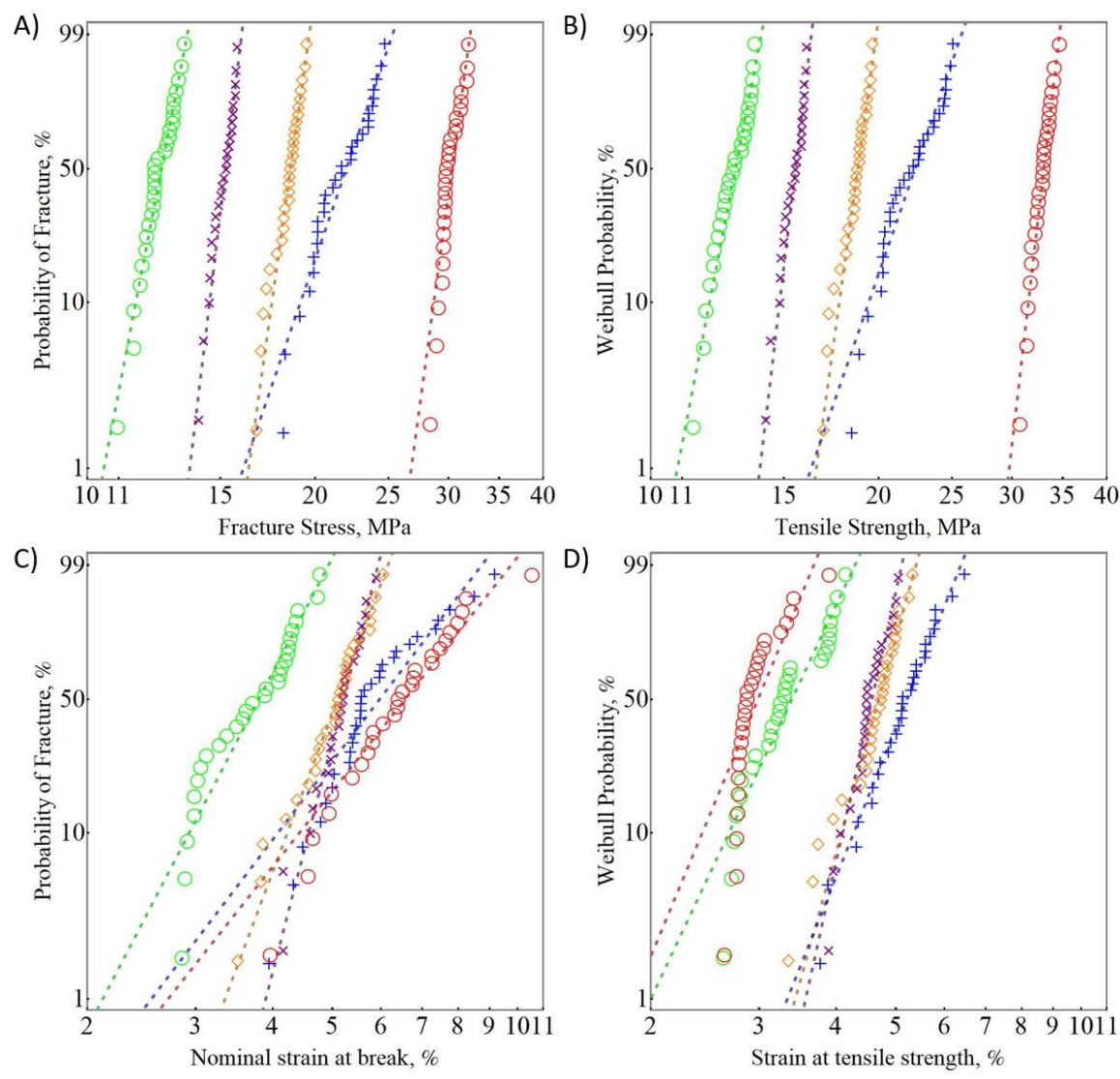

Figure 4. Weibull distribution of $20 \%$ (green circle), $40 \%$ (purple $x$ ), $60 \%$ (orange diamond), $80 \%$ (blue +), and $100 \%$ (red circle) infill percentages. A) Fracture stress, B) tensile strength, C) strain at break, and D) strain at tensile strength are shown.

The linearized Weibull distribution is shown in Figure 4. The dotted lines represent the linearized Weibull distribution. The slopes of the line (the Weibull modulus $m$ ) represent the variation in tensile stress or strain for each infill percentage. With the exclusion of the $80 \%$ infill, there was not a statistically significant difference between infill percentages for $\sigma_{f}$ and TS. The $80 \%$ infill showed an $m=14$ for $\sigma_{f}$ and $m=13$ for TS, whereas the other infills ranged from $m=24-39$ for $\sigma_{f}$ and $m=24-40$ for TS. These low $m$ values mean a large scatter in $\sigma_{f}$ and TS values. 
Like past results $[29,37,38]$, the strain values show lower $m$ values compared to strength values. The $\epsilon_{f}$ showed an increasing trend with increasing density. The $100 \%$ infill showed the lowest $\epsilon_{T S}$ of $3.1 \%$, breaking the trend of increasing $\epsilon_{T S}$ with infill percentage.

In our previous study, we reported similar $m_{f}$ and $m_{T S}$ values for short carbon-fiber composite samples at the same infill parameter settings [18, 37, 38]. The short carbonfiber ABS results gave an $m$ value range of 19-40 for fracture stress, whereas the clean ABS results showed a similar distribution of $m=14-39$. A previous study on a Stratsys uPrint showed a fracture stress range of $m=46-67$. This suggests that the Stratsys uPrint produces more reliable samples then the inexpensive RoaddogLabs Prusa i3 Baja rework.

The strain at fracture $m$ value was much lower than previous carbon-fiber composite results. This would correlate with the idea that composite samples fracture in a brittle manner compared to the clean ABS's more ductile fracture. It can be seen from Figure 2 that as density increases, the stress strain shows an increasingly plastic behavior. This would explain the $80 \%$ and $100 \%$ infills' very inconsistent strain-at-fracture values.

Table 3 Summary of Results from FDMed ABS Study

\begin{tabular}{|c|c|c|c|c|c|c|c|c|}
\hline \multirow[t]{2}{*}{ Infill } & \multicolumn{2}{|c|}{$\begin{array}{l}\text { Fracture } \\
\text { Stress }\left(\sigma_{\mathrm{f}}\right)\end{array}$} & \multicolumn{2}{|c|}{$\begin{array}{c}\text { Tensile } \\
\text { Strength }\left(\sigma_{\mathrm{TS}}\right)\end{array}$} & \multicolumn{2}{|c|}{$\begin{array}{r}\text { Strain at } \\
\operatorname{Fracture}\left(\epsilon_{\mathrm{f}}\right)\end{array}$} & \multicolumn{2}{|c|}{$\begin{array}{c}\text { Strain at } \\
\text { Tensile } \\
\text { Strength }\left(\epsilon_{\mathrm{TS}}\right)\end{array}$} \\
\hline & $m$ & $\mathrm{~S}_{\mathrm{O}}$ & $m$ & $\mathrm{~S}_{\mathrm{O}}$ & $m$ & $\mathrm{~S}_{\mathrm{O}}$ & $m$ & $\mathrm{~S}_{\mathrm{O}}$ \\
\hline $20 \%$ & 24 & 12.7 & 24 & 13.1 & 7 & 4.0 & 8 & 3.5 \\
\hline $40 \%$ & 39 & 15.4 & 39 & 15.7 & 15 & 5.3 & 17 & 4.7 \\
\hline $60 \%$ & 33 & 18.8 & 34 & 19.0 & 10 & 5.3 & 14 & 4.8 \\
\hline $80 \%$ & 14 & 22.6 & 13 & 23.0 & 5 & 6.4 & 9 & 5.4 \\
\hline $100 \%$ & 34 & 30.6 & 40 & 33.3 & 5 & 7.1 & 9 & 3.1 \\
\hline
\end{tabular}


Along the side of the tensile test coupon, a periodic crazing pattern can be seen. This is shown with the $20 \%$-infill specimen in Figure 5. The infill pattern generated by Slic3r produces regions in which the infill runs along the perimeter and portions in which it does not. This is clearly shown in Figure 5C, where a large weld can be seen running along the perimeter of the part and white crazing where the infill does not run along the perimeter. Figure 5A shows a computer-generated depiction of the infill pattern where the portions in which the infill does not run along the perimeter are highlighted in red. The red portions correlate closely with the periodic crazing seen along the side of the tensile test specimen.

A)

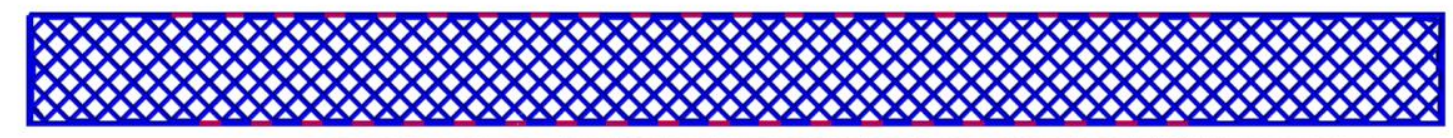

B) Inis ran.

C)

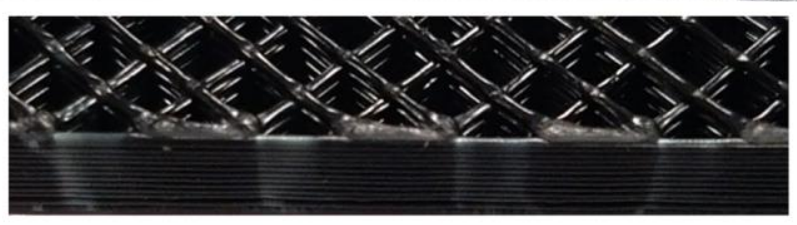

Figure 5. a) A visualization of the G-code for the $20 \%$ infill pattern. Areas where the infill does not run parallel with the parameter is highlighted in red. b) A side profile of a broken $20 \%$ infill tensile test coupon. Periodic crazing can be seen along the side of the sample. c) An only-20\%-infill specimen was printed and tensile tested. Crazing is shown in the portion where the infill does not run parallel with the perimeter.

\subsection{Conclusion}

In this chapter, the mechanical properties of five data sets of varying porosities are given. These values, summarized in Table 3, can be used by slicing software to make intelligent design choices, producing parts at higher safety and efficacy for users and designers. A deviation from a linear change is shown with the $100 \%$ infill parameter. 
This suggests a strengthening mechanism that deviates from the strengthening caused by a reduction in porosity. The author suggests that the strengthening is caused by the fusing of two neighboring beads. Finally, significant crazing patterns were shown in defined locations on the tensile specimens. This suggests that the infill pattern localizes stress on the single perimeter surface and that shifting layers could distribute the load through a larger portion of the material and increase strength and reliability. 


\section{CHAPTER SIX \\ STOCHASTIC FRACTURE OF ADDITIVELY MANUFACTURED POROUS COMPOSITES}

This section presents a reproduction of the experiment from the previous section with SCFR-ABS. One way to address the mechanical property deficiencies of FDMed ABS is to include continuous or short fibers. This has been shown to improve mechanical properties over clean ABS; however, it has shown problems of nozzle wear and increased inner-bead porosity [19].

In this study, the author used 3DXTech SCFR-ABS feedstock. Unlike other FDM composite literature, the researchers do not make their own composite material $[19,51$ 53] because they wish to give a representation of the mechanical properties of consumergrade material produced by a consumer-grade printer. One side effect is a more porous feedstock than in related studies. This commercial composite feedstock not only produced parts with lower $\sigma_{f}$ values than literature but has also reduced mechanical properties, compared to the clean ABS results presented in chapter five. This would not be the case with a denser filament; however, to this author's knowledge, no such filament is commercially available.

\subsection{Introduction}

FDMed ABS material shows reduced mechanical properties compared to injection molding [48]. One common way to address the mechanical deficiencies of FDMed ABS is to composite the material with short carbon fibers $[19,53-55]$, continuous fibers [56, 57], graphite [52], and graphene [58]. Of these reinforcing agents, short carbon fiber is the most studied. Effects of processing parameter, carbon-fiber content, fiber length, and 
raster orientation have been reported for FDMed SCFR-ABS [19, 51-55]. These studies, however, were performed with a sample size ranging from 5 to 12 , which is not statistically significant enough to investigate the stochastic fracture of FDMed SCFRABS. A large sample set $(\mathrm{N}>20)$ is required to estimate the estimate mechanical properties with low relative error [59]. The scatter of Weibull moduli drastically decreases as the sample sizes exceeds 20; however, the diminishing returns as the sample size approaches 40 . For instance, the relative layer decreases by $4 \%$ from 27 to 40 but only decreases $5 \%$ from 40 to 80 [59].

In this section, researchers investigate the effect of porosity and raster orientation on the stochastic fracture of FDMed SCFR-ABS. Five porosity levels between $13 \%$ and 53 $\%$ by volume were tested. Each test cell contained a minimum of 27 specimens per bath for a total of 241 tests. The filament was also tested as received, for a total of 90 tests. The short carbon-fiber filament has a brittle behavior under tensile load. Therefore, Weibull statistics were used to quantify variations of the mechanical properties.

Experimental strength data were used to set up micro-mechanical strength-simulation framework, which revealed the origin of variation in mechanical properties. Fractography was performed using an electron-scanning microscope (SEM), and x-ray microscopy was used to access the variations in pores in FDMed composites.

\subsection{Materials and Methods}

Two sets of filaments were bought from 3DXTech (Michigan, US). These sets are called material 1 (M1) and material 2 (M2). M1 was purchased one year before M2. This 
study repeated the $20 \%, 40 \%, 60 \%, 80 \%$, and $100 \%$ infill test cells; however, it introduces a $0^{\circ}$ raster orientation.

A theoretical density of $1.08 \mathrm{~g} / \mathrm{cm} 3$ was calculated using $6.5 \%$ carbon fiber (obtained by micro x-ray CT analysis). Using this theoretical density and taking the mass and volume of the tensile pieces, porosity was calculated using the following Equation 3:

$$
\text { Porosity }(\%)=\frac{1.08 \frac{\mathrm{g}}{\mathrm{cm}^{3}}-\text { Measured Density }}{1.08 \frac{\mathrm{g}}{\mathrm{cm}^{3}}} \quad \text { Equation } 3
$$

Thirty tensile tests were produced for the filament as received for M1 and M2, and extruded M1 filament. Samples that broke at the grips were not included in the population; therefore, a total of 90 valid samples are reported.

Two-cm segments of M1 filament were taken before and after extrusion and left to dissolve in $10 \mathrm{~mL}$ of reagent-grade acetone. The solution was then pipetted onto a glass slide for viewing in an Olympus SZX10 Stereo Microscope at 20x magnification. Image 2 [60] software was used to digitally measure the length of $\sim 200$ carbon fibers.

The ZEISS Xradia 410 Versa X-ray microscope was used for the 3-D data acquisition $[35,36]$. Two-dimensional (2-D) x-ray radiographs were automatically collected across uniformly spaced angular positions and composited into a 3-D model using ZEISS XMReconstructor software [61]. Approximately 1,600 radiographs with dwell times of 10 to 15 seconds were taken. The total acquisition and reconstruction times were 5-7 hours for each sample. Three phases were identified in the constructions: polymer matrix, carbon fiber, and pores. 


\subsection{Results and Discussion}

Five different sources of pores were discovered from the digital images and x-ray

computed tomography (Figure 6, Figure 7). These pore sources are: a) designed porosity for infill $<100 \%$; b) inter-bead porosity due to the lack of complete geometric filling between beads; c) inner-bead porosity inherited from the as-received filament; d) innerbead porosity due to flow incompatibility between ABS and carbon fiber; and e) innerbead porosity due to pores generated during high-temperature extrusion. The inter-bead porosity was controlled by adjusting the infill percentage in the slicing program. The infill percentage dictates the attempted spacing in between beads, with $100 \%$ infill denoting that the beads are touching. A $100 \%$ infill represents a nominally dense material, while a $<100 \%$ infill represents a rectilinear lattice structure. Examples of 20 $\%$ and $80 \%$ infill are given in Figures $6 \mathrm{a}$ and $6 \mathrm{~b}$. These intentional pores are the largest pores in FDMed composites.

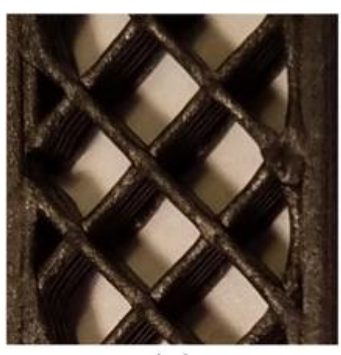

(a)

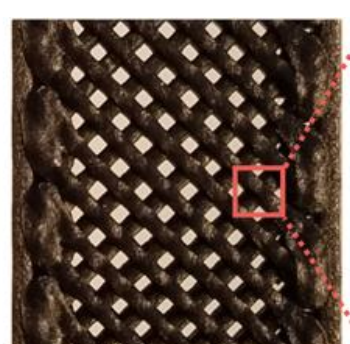

(b)

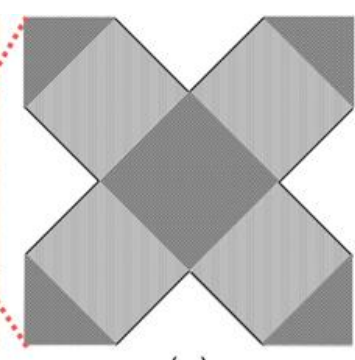

(c)

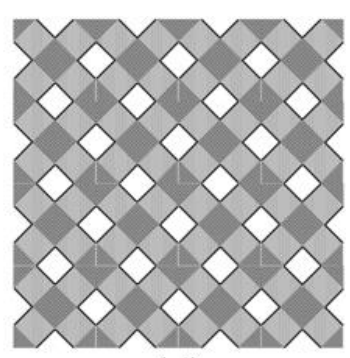

(d)

Figure 6. Photographs of internal structure of: a) $20 \%$; b) $80 \%$; c) a representational subsection of the $80 \%$ microstructure; d) simulated $80 \%$ infill structure. Adopted from O. Keles et. al. [37]. 


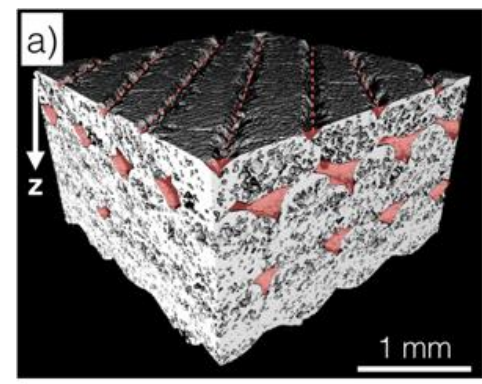

d)

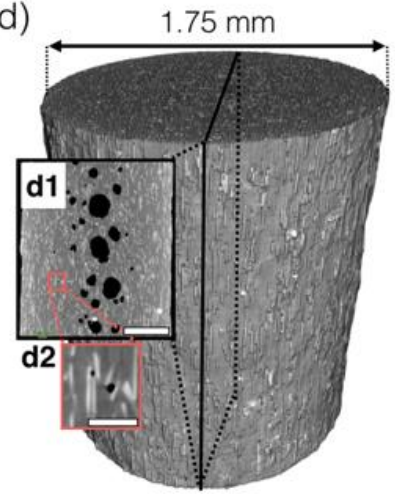

e)
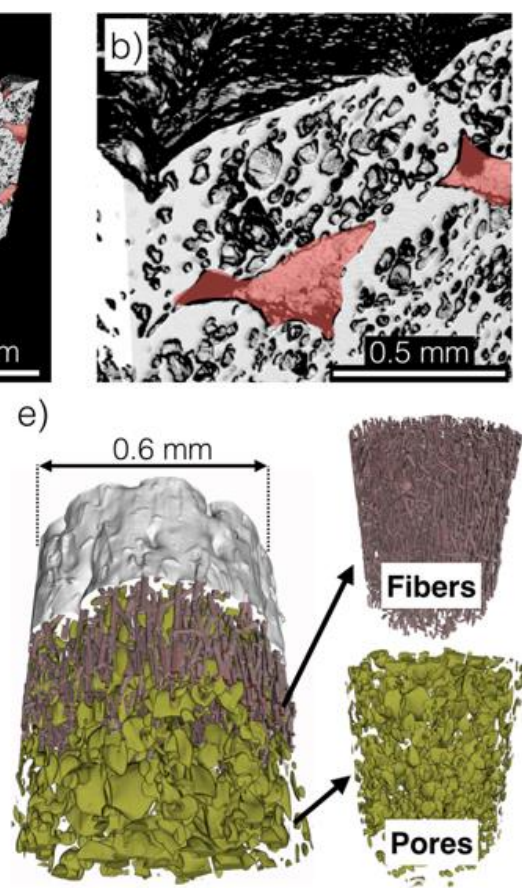

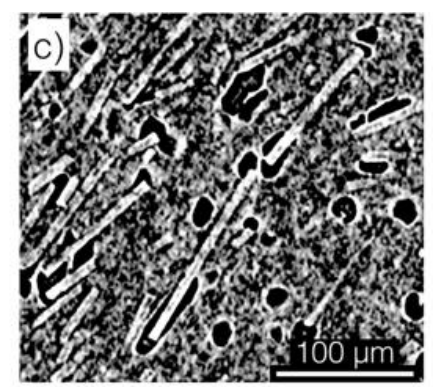

f)

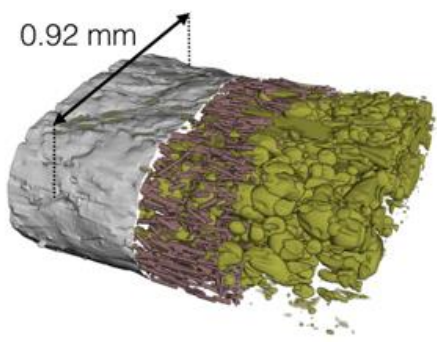

Figure 7. X-ray computed tomography of a) $100 \%$ infill of FDMed SCFR ABS (interbead pores are highlighted in red); b) $100 \%$ infill showing inner-bead pores and interbead pores highlighted in red; c) images showing a porous interface between carbon fibers and ABS matrix; d) image of SCFR-ABS as feedstock as-received; d1) crosssection plane of the filament, showing a porous core; $\mathrm{d} 2$ ) images of pores at the carbonfiber ABS interface in the as-received feedstock; e) extruded filament into air (gray denotes the ABS matrix, red the fibers, and green the pores); f) extruded bead onto a heated bed. Adopted from O. Keles et. al. [37].

Despite being set to $100 \%$ infill, the circular nozzle cannot fully complete the volume of the desired part. This is exemplified in Figures $7 \mathrm{a}$ and $7 \mathrm{~b}$. The inter-bead porosity can be reduced by deposition path algorithms [62], using a thermally expandable second-phase in filament [63], and by over-extruding to fill inter-bead pores at an infill percentage higher than $100 \%$. In this study, no attempt was used to reduce the inter-bead porosity at $100 \%$. Therefore, the inter-bead pores are the largest pores in the $100 \%$ infill. Inter-bead pores form triangulated pores that run the length of the neighboring bead's deposition. The widths and shapes of these pores are variable, dictated by nozzle 
size, layer thickness, and extrusion temperature. The total porosity for the $100 \%$ infill sample was $15 \%$ by volume for M1 and $13 \%$ for M2. If one subtracts the inherited $~ 5 \%$ porosity by volume of the extruded filament, then one can roughly estimate that $8 \%-10$ $\%$ of the fully dense material is comprised of inter-bead pores.

The author observed large Figure $7 \mathrm{~b}$ and small Figure $7 \mathrm{c}$ inner-bead porosity. Large inner-bead pores $(>50 \mu \mathrm{m})$ were inherited from the as-received filament (Figure $7 \mathrm{~d} 1$ ). The $\mathrm{x}$-ray $\mu \mathrm{CT}$ reconstruction shows that the filament contained $\sim 5 \%$ porosity by volume. These pores were entrapped during the deposition and printed along with the carbon fibers. The sphere-like pores in the as-received filament became elongated during extrusion (Figures $7 \mathrm{e}$ and $7 \mathrm{~d}$ ). Small pores at the fiber ends were also present in the filament before (Figure 7d2) and after (Figure 7c) extrusion. Small pores at the fiber ends are caused by flow mismatch between the fibers and ABS [19]. Increasing the nozzle temperature from $200{ }^{\circ} \mathrm{C}$ to $240{ }^{\circ} \mathrm{C}$ has been previously reported to increase the interbead porosity in SCFR-ABS [52]. Researchers use the material supplier's (3DXTech's) recommended nozzle temperature of $235^{\circ} \mathrm{C}$. This high temperature could have caused higher inner-bead porosity. The relative ratios of inner-bead between porosity inherited from the filament, pores at the fiber ends, and pores generated from the high thermal expansion are challenging to quantify.

The extrusion of the as-received filament increased its porosity from 5 vol. $\%$ to $\sim 20$ $\%$ for air extrusion and $\sim 22$ vol. $\%$ for deposition on the hot printed bed. These values were obtained by x-ray CT data and are larger than the $13 \%-15 \%$ of the total porosity of the $100 \%$ infill samples. This is caused by a reduction in porosity as the print head 
moves away from the heated bed (Figure 7e). There was fluctuating porosity from the asreceived filament (Figure 7e). In the remainder of the discussion, "porosity" refers to total porosity.

Tensile tests were conducted on seven populations of FDMed SCFR-ABS, containing a minimum of 27 replicates. The total number of tensile tests conducted was 241 . This information is summarized in Table 4. The nominally dense sample had $100 \%$ infill and average fracture stress $\left(\sigma_{f}\right)$. As the porosity increased, $\sigma_{f}$ and TS decreased (Figure 8). The effects of infill percentage on the TS of FDMed ABS have been reported by Fernandez-Vincente et al. [24]. In that ABS study, the TS of the $20 \%, 50 \%$, and $100 \%$ infills were reported to 16,20 , and $36 \mathrm{MPa}$ for the $20 \%, 50 \%$, and $100 \%$ infills, respectively. These TS data fit the function $\sigma_{p} \cong 15+.002 x^{2}$, where $\sigma_{p}$ is the TS and $x$ is the density. The researchers fit the same function to the FDMed SCFR-ABS and obtained a $\sigma_{p} \cong 11+.001 x^{2}$ with an $R^{2}=0.99$. The SCFR ABS showed a lower dependence on infill than the ABS. This is due to a higher volume percent of inner-bead (Figures $9 \mathrm{~b}$ and 9c) pores and the larger inter-bead pores (Figure 9a) created by the larger composite nozzle. 
Table 4 Summary of Results from FDMed SCFR-ABS Study

\begin{tabular}{|c|c|c|c|c|c|c|c|c|c|c|}
\hline \multirow[t]{2}{*}{$M$} & \multirow{2}{*}{$\mathrm{P}(\%)$} & \multirow[t]{2}{*}{$\mathrm{E}(\mathrm{GPa})$} & \multicolumn{2}{|c|}{$\sigma_{f}(\mathrm{MPa})$} & \multicolumn{2}{|c|}{ TS (MPa) } & \multirow{2}{*}{$\begin{array}{c}\epsilon_{f}(\%) \\
\mathrm{m}\end{array}$} & \multicolumn{3}{|c|}{$\epsilon_{T S}(\%)$} \\
\hline & & & $\mathrm{m}$ & $\sigma_{o}$ & $\mathrm{~m}$ & $\sigma_{o}$ & & $\sigma_{o}$ & $\mathrm{~m}$ & $\sigma_{o}$ \\
\hline \multirow{3}{*}{1} & & & 24 & & 23 & & 11 & & 28 & \\
\hline & $15 \pm 4$ & $2.5 \pm .01$ & $(19-30)$ & 23 & $(18-29)$ & 23 & $(9-14)$ & 3.7 & $(22-36)$ & 3 \\
\hline & & & 25 & & 24 & & 21 & & 26 & \\
\hline \multirow[t]{2}{*}{1} & $25 \pm 3$ & $2.1 \pm .01$ & $(20-30)$ & 20 & $(20-30)$ & 20 & $(17-26)$ & 3.2 & $(21-32)$ & 2.9 \\
\hline & & & 18 & & 18 & & 15 & & 18 & \\
\hline \multirow[t]{2}{*}{1} & $34 \pm 2$ & $1.9 \pm .009$ & $(15-21)$ & 16 & $(15-21)$ & 16 & $(12-19)$ & 2.4 & $(15-22)$ & 2.3 \\
\hline & & & 36 & & 41 & & 11 & & 12 & \\
\hline \multirow[t]{2}{*}{1} & $41 \pm 1$ & $1.7 \pm .008$ & $(30-44)$ & 13 & $(34-49)$ & 13 & $(9-14)$ & 2.3 & $(10-15)$ & 2.3 \\
\hline & & & 39 & & 41 & & 8 & & 9 & \\
\hline \multirow[t]{2}{*}{1} & $53 \pm 1$ & $1.5 \pm .008$ & $(32-48)$ & 11 & $(33-51)$ & 11 & $(7-10)$ & 1.9 & $(7-11)$ & 1.8 \\
\hline & & & 40 & & 46 & & 17 & & 10 & \\
\hline \multirow[t]{2}{*}{2} & $23 \pm 3$ & $5.0 \pm .004$ & $(35-52)$ & 32 & $(36-61)$ & 33 & $(13-22)$ & 2.4 & $(14-25)$ & 2 \\
\hline & & & 19 & & 19 & & 9 & & 8 & \\
\hline 2 & $13 \pm 3$ & $3.0 \pm .003$ & $(15-24)$ & 24 & $(15-25)$ & 24 & $(8-12)$ & 2.8 & $(6-10)$ & 2.7 \\
\hline
\end{tabular}




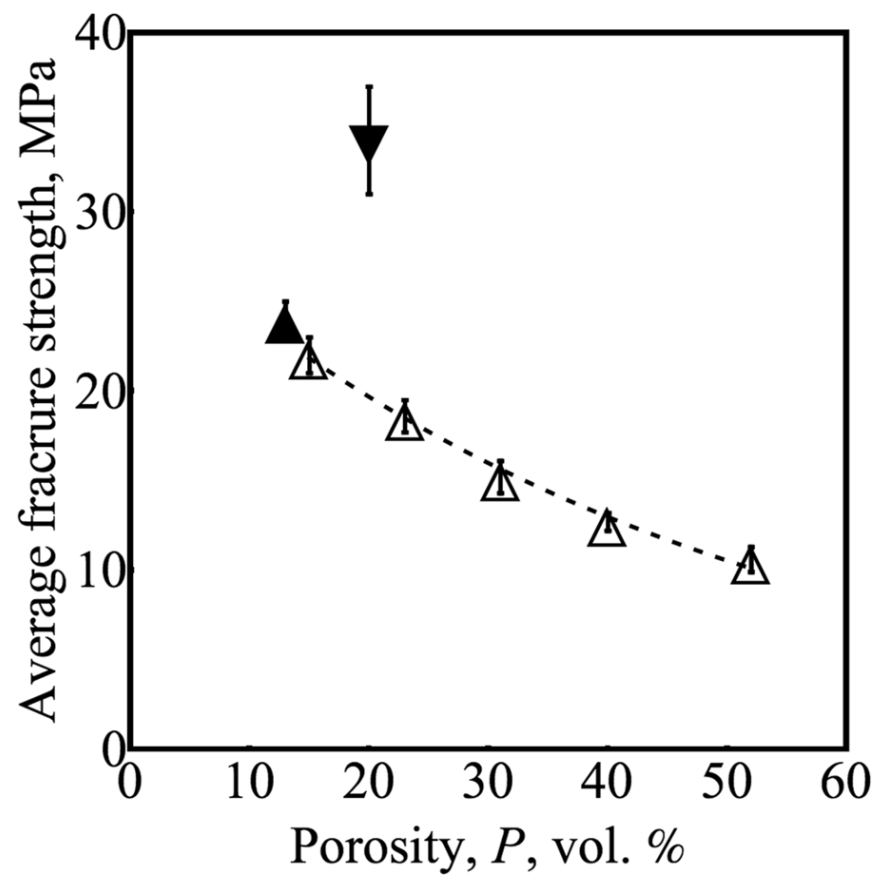

Figure 8. Effect of porosity on the average fracture strength of FDMed SCFR-ABS. The symbol $\Delta$ represents M1, and $\boldsymbol{\Delta}$ represents M2. The symbol $\boldsymbol{\nabla}$ represents M2 with $0^{\circ}$ bead orientation. The dotted trendline represents a fit of the form $\sigma_{o} \operatorname{Exp}[-b P]\left(\sigma_{0}=\right.$ $30 M P a, b=0.02)$ with an $\mathrm{R}^{2}=0.99$. Error bars represent one standard deviation. Adopted from O. Keles et. al. [37].
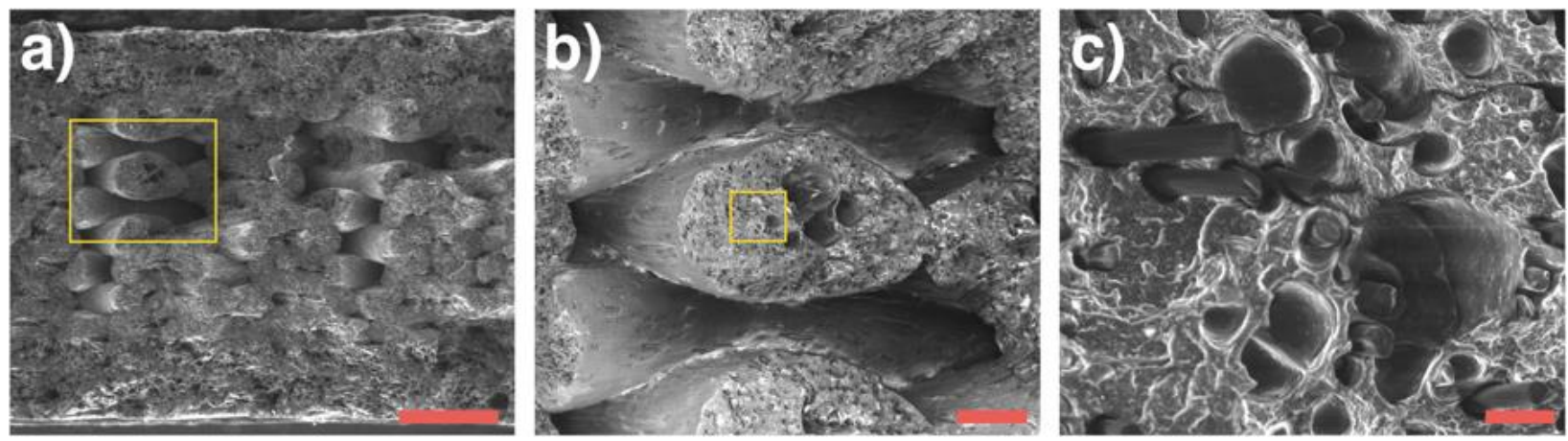

Figure 9. SEM micrographs of the fracture surface of the nominally dense $10 \%$ infill, including photos of a) inter-bead porosity; b) fiber pores; and c) inner-bead porosity. Scale bars correspond to $1 \mathrm{~mm}, 200 \mu \mathrm{m}$ and c) $20 \mu \mathrm{m}$. Adopted from O. Keles et. al. [37]. 
The FDMed SCFR-ABS tested showed a brittle fracture behavior with little plasticity. The difference between the tensile behavior between ABS and SCFR-ABS can be attributed to strong pore-to-pore interactions within inner-bead pores. The most porous samples $(52,40$, and 31 vol. \%) showed to be the most brittle samples, with statistically identical $\epsilon_{T S}$ and $\epsilon_{f}$ (Table 4). The denser samples showed limited plasticity of $4.5 \%$ between $\epsilon_{T S}$ and $\epsilon_{f}$. Therefore, the researchers commonly use Equation 4 to describe the relationship between $\sigma_{f}$ and Porosity (P) for brittle systems (Figure 8) [64, 65]. In this expression, b represents the sensitivity of $\sigma_{f}$ to P. Studies have reported this sensitivity factor to range from .015 and .074 [66]. These experimental data give a b value of .02 , between porous glass and alumina [66].

$$
-\sigma_{f}=\sigma_{o} \operatorname{Exp}[-b P]
$$

Equation 4

Raster orientation defines the direction of inter-bead pores and fiber. This has been shown to greatly impact the physical properties of FDMed materials [38, 67]. In this context, the author studies the effect of adjusting the raster orientation from $-45^{\circ} / 45$ to $0^{\circ}$ on the mechanical properties and reliability of SCFR-ABS. In the $0^{\circ}$ degree orientation, all infill beads are pointed in the direction of tensile load. This strengthens the material by more efficiently transferring the load to the short carbon fibers that now run parallel to the tensile load, increasing the cross-sectional area, and the inter-bead pores have reduced stress concentration due to their orientation. As a result, the change in raster orientation from $-45^{\circ} 45^{\circ}$ increased the TS by $42 \%$ and increased the elastic modulus by $67 \%$ (Table 4). 
The $0^{\circ}$ raster orientation in this study was $\sim 30 \%$ lower than the $0^{\circ}$ reported by Telknip et al. [19]. This is mainly due to the reduced fiber length $91 \pm 52 \mu \mathrm{m}$ and $77 \pm$ $44 \mu \mathrm{m}$ compared to the $\sim 250 \mu \mathrm{m}$ and 23 vol. \% porosity reported (Table 4). Extrusion out of the $0.6 \mathrm{~mm}$ reduced the as-received filament from $117 \pm 65 \mu \mathrm{m}$ to $91 \pm 52 \mu \mathrm{m}$ (22 $\%$ reduction) and $148 \pm 76 \mu m$ to $77 \pm 44 \mu m$ (a $48 \%$ decrease). The change in fiber length before and after extrusion is shown in Figure 10. The average fiber diameter is 6$8 \mu m$ based on X-ray CT analysis. The researchers calculate that the critical fiber length $\left(l_{c}\right)$ ideally would be between $216 \mathrm{MPa}$ and $576 \mathrm{MPa}$, according to $l_{c}=\frac{\sigma_{\text {fiber }} d}{2 \tau_{m}}[68]$ by assuming the carbon fiber strength $\sigma_{\text {fiber }}=2.16 \mathrm{GPa}[69]$ and the fiber-matrix interface shear strength $\tau_{m}=30-15 \mathrm{MPa}$ [19]. Effective strengthening of ABS with short fibers requires lengths higher than $l_{c}$ (i.e., higher in aspect ratio) [70]. For example, increasing the composite by a factor of 10 would strengthen it up to $95 \%$ [71]. 


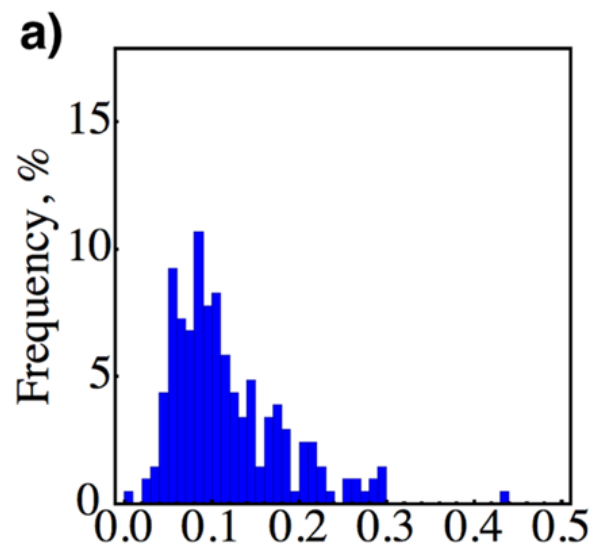

Fiber length, $\mathrm{mm}$

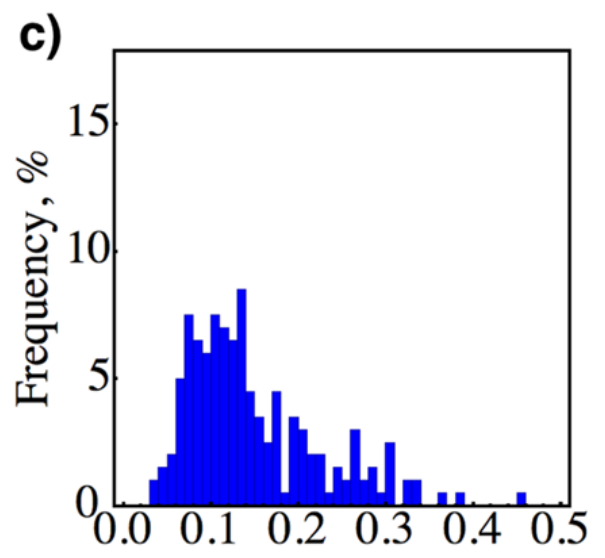

Fiber length, mm

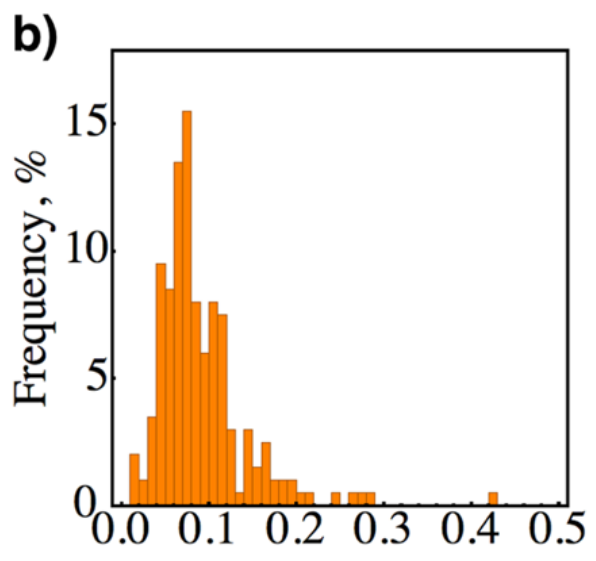

Fiber length, $\mathrm{mm}$

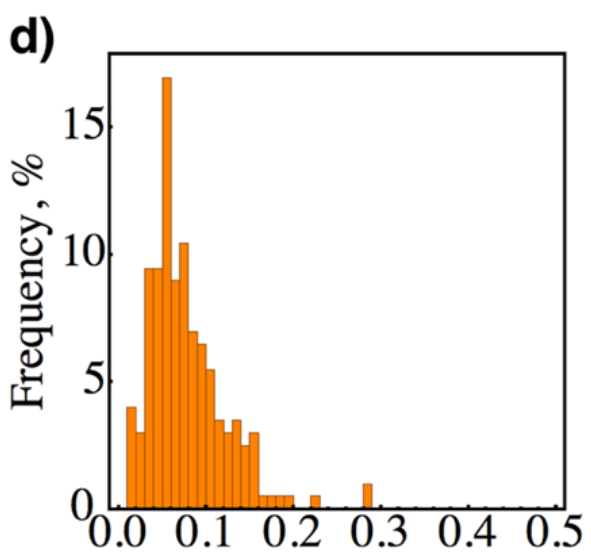

Fiber length, $\mathrm{mm}$

Figure 10. Fiber-length measurements after filament was dissolved in reagent grade acetone (a) and raw filament (c). Extruded filament (b and d). Adopted from O. Keles et. al. [37].

In order to quantify mechanical reliability, $\sigma_{f}, T S, \epsilon_{f}, \epsilon_{T S}$ were analyzed using Weibull statistics. These data were plotted and fitted with a dotted line showing the Weibull distribution (Figure 11, Table 4). The slopes of these Weibull distributions fit; the Weibull modulus $(m)$ quantifies the variation in test results. There was no meaningful difference in variation in $\sigma_{f}$ and TS for orientation for all seven test populations. In other words, the $\sigma_{f}$ and TS showed similar dependence on $P$ and raster orientation (Figure 11). The lowest Weibull modulus for $\sigma_{f}\left(m_{\sigma_{f}}\right)$ was with $\mathrm{P}=34$ vol $\%$ and $m_{\sigma_{f}}=18$. This 
data set deviates at higher fracture stresses. An argument could be made that for engineering design purposes, the two higher fracture points could be removed from the data set because variations into higher stress are inconsequential for design applications, and the variability may be misleading and decrease the feasibility of that infill parameter. When these two high-stress data points are removed from the $P=34 \mathrm{vol} \%$, the Weibull moduli increases from $m_{\sigma_{f}}=18$ to 23 , which is nominal to the other infill percentages. The populations of Weibull moduli were as low as technical ceramics (Figure 12). These large $m$ values mean there is a large scatter of $\sigma_{f}$ and TS, a $22 \%$ difference between the strongest and weakest samples in the $\mathrm{P}=13 \mathrm{vol} \%$. 

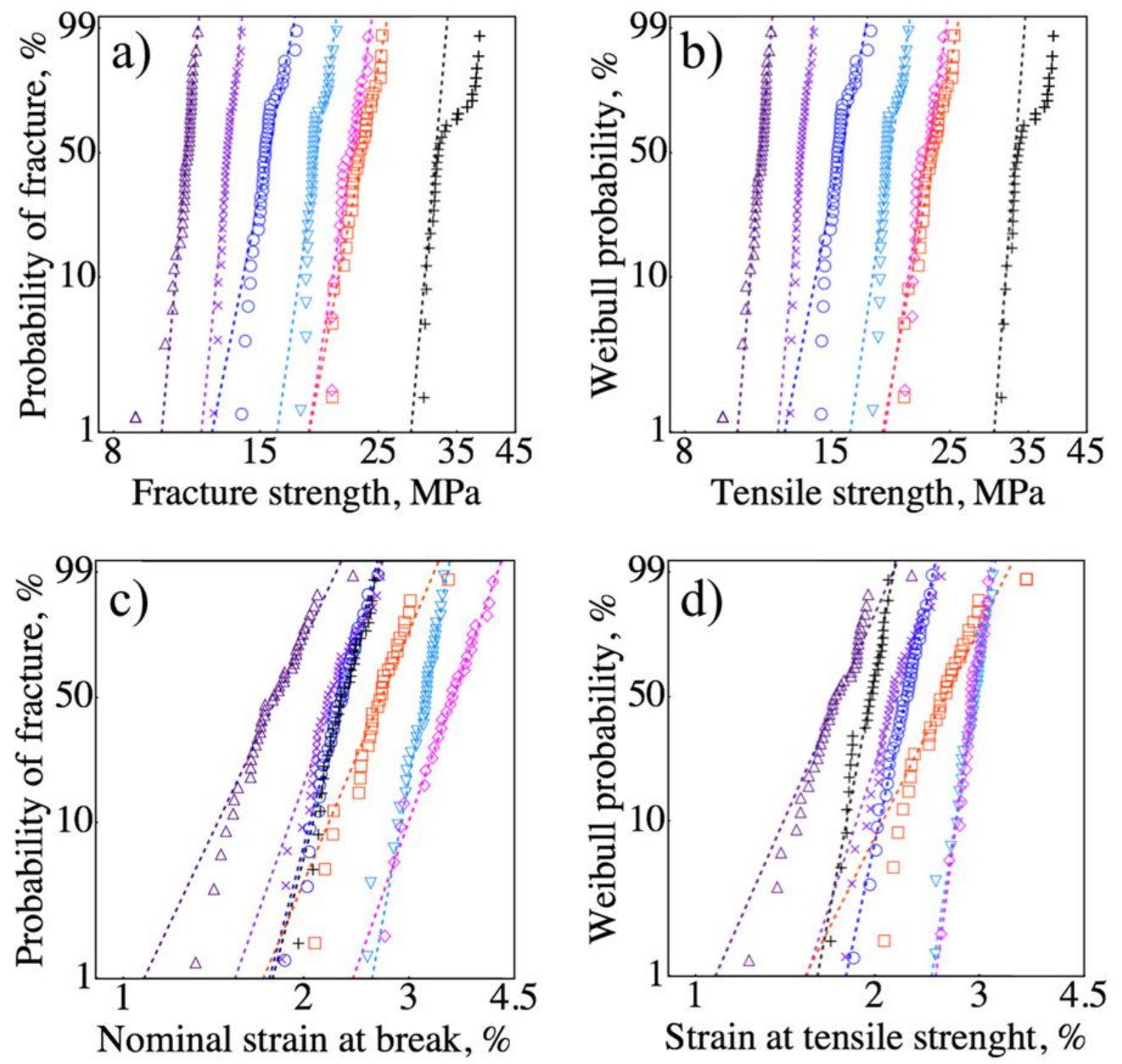

Figure 11. Weibull distribution plot of a) fracture strength; b) tensile strength; c) nominal strain at break; d) strain at tensile strength for FDMed SCFR-ABS. M1 P $=53$ vol. $\% \Delta$, $\mathrm{P}=41$ vol. $\% \times, \mathrm{P}=34$ vol. $\% \bigcirc, \mathrm{P}=25$ vol. $\% \nabla, \mathrm{P}=15$ vol. $\% \diamond$, for $\mathrm{M} 2 \mathrm{P}=13$ vol. $\%$ $\square$, and $\mathrm{P}=23$ vol. $\%+$. Adopted from O. Keles et. al. [37]. 


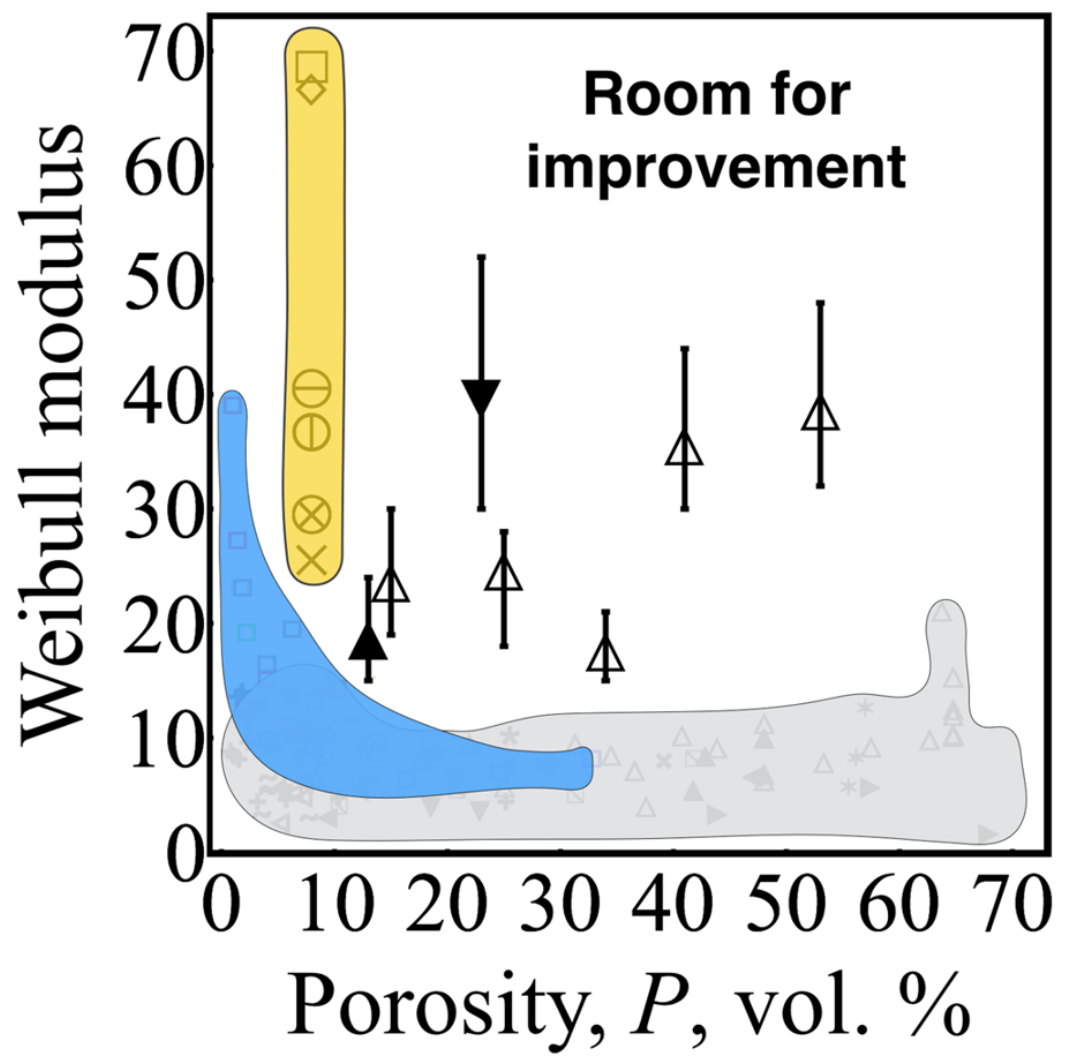

Figure 12. Effect of porosity on the Weibull modulus FDMed-SCFR composites; $\Delta$ is for M1, $\boldsymbol{\Delta}$ is for material 2 at $100 \%$ infill, and $\boldsymbol{\nabla}$ is for M2 at $100 \%$ infill in $0^{\circ}$ raster orientation. Error bars correspond to a $90 \%$ confidence interval. Yellow represents moduli of FDMed ABS built in different orientations [18]. Gray represents experimental moduli of various porous ceramics [72]. Blue represents simulated modulus of brittle porous materials [72]. Adopted from O. Keles et. al. [37].

The Weibull moduli for strain was lower than that of strength (Figure 12, Table 4). The $m_{\epsilon_{f}}$ values for the dense specimens were 11 for M1 and 9 for $\mathrm{M} 2$. The strain values for M1 ranged from $2.7 \%$ to $4.1 \%$, a $34 \%$ difference. The $m_{\epsilon_{f}}$ increased with porosity within the range of $\mathrm{P}=25$ to $53 \mathrm{vol} . \%$. Similarly, the $m_{T S}$ decreased with increasing porosity from 15 to 53 vol. $\%$.

The $m$ values of composites were higher than porous ceramics (Figure 12). These results are comparable to those reported in chapter six; however, they are lower than 
those reported in previous studies: 46 and 67 for dense ABS in XY raster orientation [18]. This suggests that the printer resolution, nozzle diameter, and heated chamber may be causes of loss in mechanical reliability.

Microstructural sources of mechanical variation with FDMed SCFR-ABS include the distribution of pore size-shape-position, distribution of position-orientation-lengthdiameter, and disruption of the inter-bead pores as a function of positional accuracy. The fracture behavior of FDMed composites depends on inter-bead pore distribution, pore-topore interaction, pore-to-fiber interaction, and fiber/matrix interactions. These defects are the source of distribution in $\epsilon_{f}$ and $\epsilon_{T S}$. In this context, the decreasing $m_{e_{f}}$ and $m_{e_{T S}}$ with increasing porosity can be attributed to low number of beads in the high-porosity sample (Figure 6). For example, if a bead contains large pores, it is unable to transfer the load to neighboring beads. A defect of this nature will experience a catastrophic failure at lower strains than samples not containing a larger pore. Samples with many neighboring beads (low $\mathrm{P}$ samples) have a narrow distribution of $\epsilon_{f}$ and, therefore, a higher Weibull modulus.

The effect of bead orientation and raster-to-contour inter-bead pores was studied with tensile tests on $0^{\circ}$ degree bead-orientation samples. Comparing the $45^{\circ} / 45^{\circ}$ to $0^{\circ}$ bead orientation nearly doubled all Weibull moduli for $\sigma_{f}, T S, \epsilon_{f}$, and $\epsilon_{T S}$ (Table 4). There is also a $\sim 25 \%$ higher strength and a $66 \%$ increase in elastic modulus compared to the $45^{\%}-45^{\circ}$ orientation (Table 4). A large batch-to-batch variance was seen in the $0^{\circ}$ samples. These samples are printed in batches of 10; the first two batches exhibited an average $\sigma_{f}$ of $\sim 30.5 \mathrm{MPa}$, while the last batch showed an average of $37 \mathrm{MPa}$. This last, higher 
$\sigma_{f}$ batch is shown by the upper-tail deviation seen in Figure 11. The author disregarded these 10 samples in order to avoid underestimating the true $m$ value. The higher $m_{\sigma_{f}}$ of the $0^{\circ}$ bead orientation, compared to $45^{\circ} \%-45^{\circ}$ bead orientation, demonstrates the effect of fiber, inner-bead, and inter-bead orientation on variability.

The mechanical properties and reliability were also studied for the as-received filament and extruded filament (Figure 13). The fracture surfaces of the as-received filament and extruded filament are shown in Figures $7 \mathrm{c}$ and $7 \mathrm{e}$. The orientation of the fibers makes it very similar to the $0^{\circ}$ bead orientation specimens. The $m_{\sigma_{f}}$ of the asreceived filament was 62 and 27 for M1 and M2, respectively. This shows that the reliability of the $0^{\circ}$ bead orientation can be as high for Weibull moduli for the as-received filament. The extruded filament showed a $m_{\sigma_{f}}$ of 23 , which is statistically the same as the dense specimens with $45^{\circ}-45^{\circ}$ bead orientation. The decrease in Weibull modulus after extrusion indicates the production of defects, such as increased porosity and decreasing fiber length (Figure 13). 


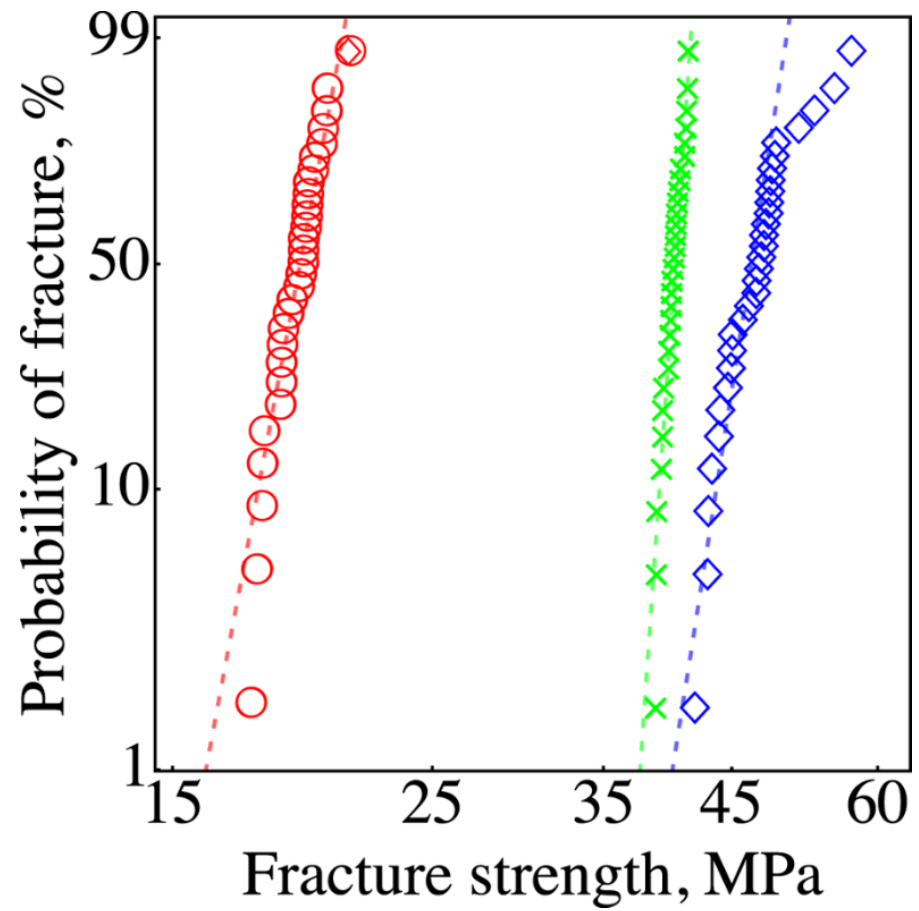

Figure 13. Weibull distribution for fracture stress of the extruded filament $(\bigcirc), \mathrm{M} 1$ filament $(\times)$, and M2 filament $(\diamond)$ Adopted from O. Keles et. al. [37].

The Anderson Darling and Pearson $\chi^{2}$ goodness-of-fit-tests were used to determine if these data fit a Weibull or normal distribution. The P-values of these tests did not indicate a preference between the Weibull and normal distributions. In order to determine a bias, a larger sample size is needed. The mechanical properties did deviate from the Weibull distribution. The origin of these deviations is difficult to isolate in a complex case of interactions of different-sized pores [38], fibers, and lattice structures.

Although the exact failure mechanisms were not proven, the researchers believe that the variations in size of the inter-bead and inner-bead pores caused scatter in mechanical properties. Variations in inter-bead porosity depend on the extrusion bead thickness and the accuracy and precision of the heated extruder. Factors that affect the extrusion bead thickness include fiber content, filament diameter, and porosity of as-received filament. 
Variations in these properties cause variations in the size and shape of inter-bead pores and are believed to vary the mechanical properties of the FDMed part.

Irregularities in extruded bead thickness are mostly properties of the as-received filament; however, irregularities in deposition accuracy and precision are functions of the FDM itself. The precision of this system is limited by stepper motors and a belt-driven system; beads can be deposited closer to or farther away from a desired location to a neighboring bead. Porosity in the feedstock not only contributes to bead thickness (and therefore inter-bead porosity), but it also affects the variations in inner-bead porosity.

Differences in the mechanical behavior of M1 and M2 were observed. M1 and M2 were sold as the same filament yet advertised improvements to the filament. The M2 asreceived filament was $\sim 17 \%$ stronger than M1 but was $22 \%$ less ductile. This shows that differences in feedstock material have a noticeable effect on mechanical properties. Therefore, a homogeneous filament is needed to achieve high mechanical reliability.

\subsection{Conclusion}

This paper reports the mechanical properties and variability of FDMed SCFR ABS as a function of porosity. The effect of raster orientation on mechanical properties was also examined. With high-resolution X-ray $\mu \mathrm{CT}$, five distinct pores are identified: pores generated by the infill parameter, inter-bead pores, inner-bead pores due to fiber-matrix mismatch, inner-bead pores in as received feedstock, and pores generated from extrusion.

The fracture strength of the FDMed SCFR-ABS decreased with increasing porosity at a rate of $\sigma_{f}=30 \operatorname{Exp}[-0.02 P]$ for $13<\mathrm{P}<53 \%$ by volume. The Weibull modulus for $\epsilon_{f}$ and $\epsilon_{T S}$ decreased with increasing porosity from 25 to 53 vol. \%. By switching the 
raster orientation from $45 /-45$ to $0^{0}$, the author showed an increase of the Weibull modulus for $\sigma_{f}, T S, \epsilon_{f}$, and $\epsilon_{T S}$ and an increase in the average $\sigma_{f}$ by $\sim 40 \%$. Extruding the $1.75 \mathrm{~mm}$ diameter filament from the $.6 \mathrm{~mm}$ nozzle decreased the carbon-fiber length from $22 \%$ to $48 \%$.

The researchers believe that one major cause of mechanical variability is the low accuracy of the printer, causing higher variability in inter-bead porosity. Higherresolution printers may be able to produce prints with lower variability in inter-bead porosity. A pore-free filament will produce more uniform inter-bead pore distributions, improving reliability. Finally, a longer fiber and stronger matrix adhesion can be achieved, causing increased mechanical reliability. 


\section{CHAPTER SEVEN \\ MECHANICAL RELIABILITY OF SHORT CABRON FIBER REINFORCES ABS PRODUCED VIA VIBRATION ASSISTED FUSED DEPOSTION MODELING}

As shown in the previous chapter, FDMed SCFR-ABS has significant room for improvement in reliability and tensile properties. As discussed in Tekinalp et al. [19], inter-bead porosity is an air pocket in between two extruded beads that the composite material was unable to fill. These triangular-shaped pore regions can act as stress concentrators and can reduce the mechanical properties of the FDM part [38]. In this chapter, a novel vibration-assisted FDM process is introduced for decreasing the interbead porosity and therefore increasing the mechanical properties of the SCRF-ABS.

Twenty-four vibrated samples were printed with identical processing parameters to the $100 \%$ infill samples in the previous chapter. The $100 \%$ infill new-material data were used as the non-vibrated control for this experiment. As in previous sections, a Weibull analysis was used to quantify variations in fracture stress, tensile stress, tensile strain, and fracture strain.

Via SEM imaging, a clear reduction in inter-bead porosity was observed over nonvibrated samples. This had the desired effect of increasing all measured mechanical properties, including a $100 \%$ improvement in mechanical reliability. These results introduce a low-cost manner of increasing the density of FDM parts, increasing their relevant applications and therefore driving the industry. These results also offer statistical data, useful as a design guideline for predicating failure rates. 


\subsection{Introduction}

Inter-bead porosity has been correlated to reduced mechanical properties and reliability $[18,19]$. Reducing this inter-bead porosity would have significant effects on the mechanical properties and reliability; however, creating a non-inter-bead FDM part is

difficult $[18,19,52]$. To address the inter-bead porosity, Qiu and Langrana et al. numerically show a reduction in inter-bead porosity via an algorithm extrusion [62]. Wang et al. used expanding microspheres to reduce the inter-bead porosity in postprocessing [63]. Although these two techniques have proven successful at reducing interbead porosity, they are effective with only smaller nozzle sizes; therefore, these techniques are not useful for composite parts. Composite filament must be printed using an FDM nozzle larger than $0.5 \mathrm{~mm}$ to avoid clogging [19]. These larger nozzles producing larger inter-bead pores cannot currently be eliminated using algorithms, microspheres, or any post-processing technique.

In this paper, the author presents a novel, cost-effective way of reducing inter-bead porosity of a $0.6 \mathrm{~mm}$ nozzle FDM printer and calls this new method the "vibrationassisted fused deposition modeling" (VA-FDM). This technique is different than the recent ultrasonic vibration-based technique, which focuses on surface finish [73]. The researchers also present the mechanical properties and reliability for this work, which can be used to aid design to make safer and higher specific stress parts. Finally, the researchers speak to the origins of variations in mechanical reliability. 


\subsection{Materials and Method}

Please see chapter 4.1.1 for all modeling descriptions; 4.1.2 for fractography descriptions; 4.1.3 for the tensile testing description; 4.1.4 for the Weibull analysis description; and 4.1.5 for the tensile dog-bone printing description. Differences in the methods from previous experiments are described below.

This study was to determine the mechanical properties with tensile test specimens printed with and without vibration. To achieve vibration, a 12-V direct-current vibrational motor with an offset 30 -g mass was attached to the heat sink of the extrusion head. The motor was connected to the FDM system in the standard fan location. This provides the advantage of turning the vibrational motor on or off with G-code, using standard fan commands (M106 S40 and M107, respectively). This provided control, allowing vibration only on the infill portions of layers 3 through 10 out of the 12 . Because the vibrational motor was now connected to the standard fan pins, the fan was relocated to an (always on) 5-V pin on the Arduino board. The resulting vibrational amplitude was $\sim .15 \mathrm{~mm}$ peak to peak. The vibrational wavelength was $4.8 \mathrm{~mm}$ at $\sim 375$ $\mathrm{Hz}$ and $2400 \mathrm{~mm} / \mathrm{min}$. The actual wavelength should be lower because of the velocity changes of the print heads during print.

A total of 47 non-vibrated specimens and 37 vibrated specimens were printed. Out of these tests, 23 of each population were valid due to fractures in the tensile test grips. Fracture stress and strain at fracture was determined only using the valid 23 samples; however, tensile strength and strain at tensile strength was reported with all printed samples. 


\subsection{Results and Discussion}

With the addition of vibrations to the FDM process, the SEM of the fracture surface shows a decrease in porosity (Figure 14). This is confirmed with density measurements, showing a reduction in total percent porosity from $13 \%$ to $10 \%$. Additional to the reduction of inter-bead pore size, a change in bead morphology is also seen. Longchanneled, triangulated pores (Figures $14 \mathrm{~b} 2$ and 14b3) become a zigzagging pattern with the potential to terminate channels against the neighboring raster (Figures $14 \mathrm{c} 2$ and 14c3]. The inter-bead porosity is changed by the vibrating head physically pushing the low viscosity material on an already-deposited bead.

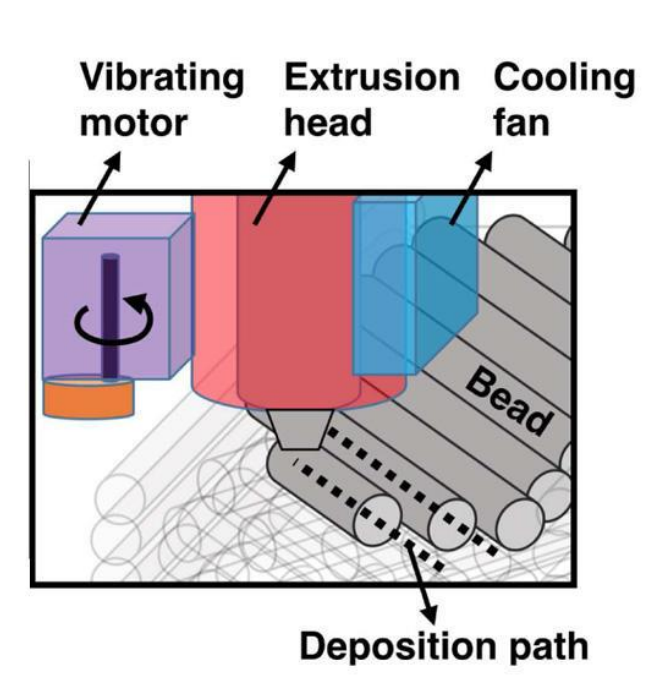

(a)

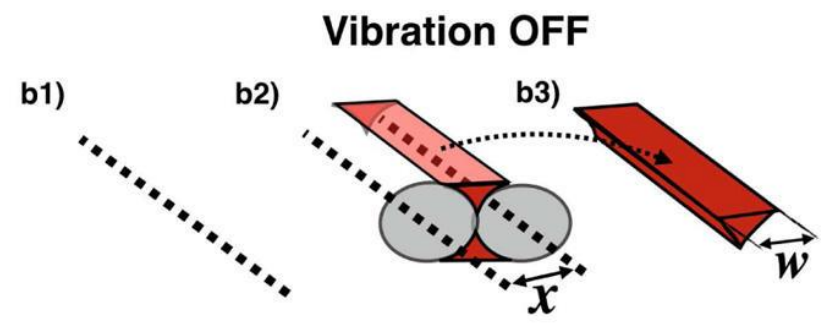

(b)

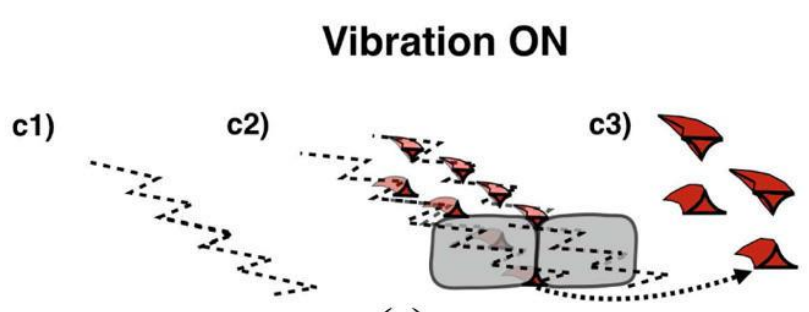

(c)

Figure 14. a) Schematic of the relative positions of the vibrational motor, extrusion head, and cooling fan, respectively; b) Depiction of the inter-bead porosity generated by the standard fused deposition modeled method; c) Depiction of the inter-bead pore generation from vibrational fused deposition modeled. Adopted from O. Keles et. al. [38]

Inner-bead porosity was seen in both the FDM and VA-FDM samples. Inner-bead porosity has been reported to be caused by both the viscosity incompatibility between the fiber and ABS plastic, as well as the temperature of the nozzle $[19,52]$. A nozzle 
extrusion temperature of $235^{\circ} \mathrm{C}$ - the temperature used in this study - has been shown to introduce inner-bead porosity. The extent of pore generation is unknown, due to being dependent on fiber concentration. In addition to this the feedstock was at $5 \%$ as received, as reported by X-ray $\mu \mathrm{CT}$ in Chapter 7.

Inter-bead porosity is the largest and highest stress concentrator in FDMed composites. Tekinalp et al. reported higher mechanical properties for compression molded SCFR-ABS, with no inter-bead porosity, than FDMed SCFR-ABS. Similarly, as inter-bead porosity was reduced via vibrations, fracture strength $\left(\sigma_{f}\right)$, tensile strength (TS), and nominal strain at break $\left(e_{f}\right)$ increased by more than $10 \%$. The elastic modulus was also increased from $2.5 \pm 0.1 \mathrm{GPa}$ to $2.7 \pm 0.1 \mathrm{GPa}$. This increase can be seen in Figure 15. The stress-strain curves for the vibrated and non-vibrated populations are shown in Figure 16. 


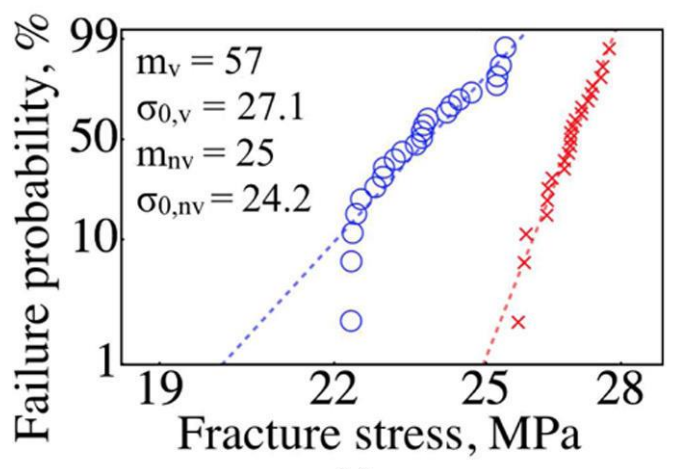

(a)

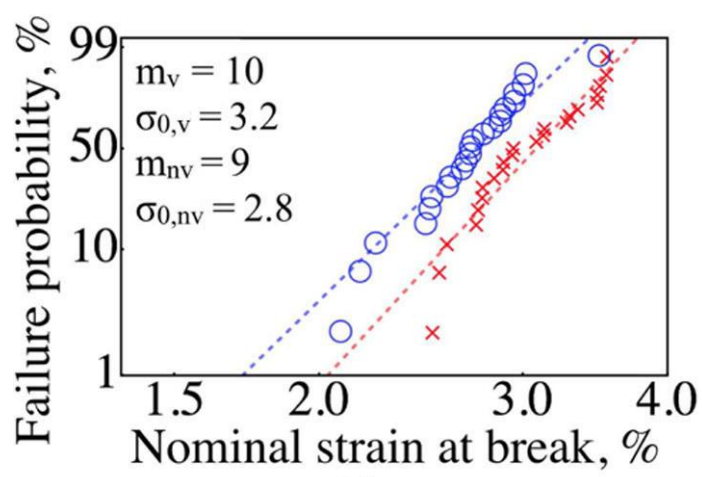

(c)

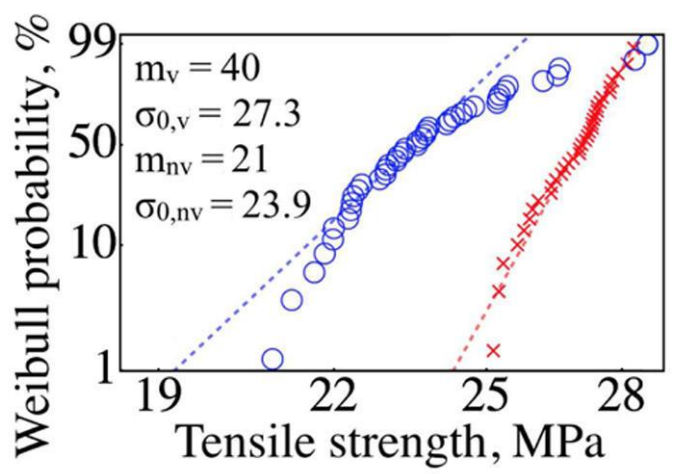

(b)

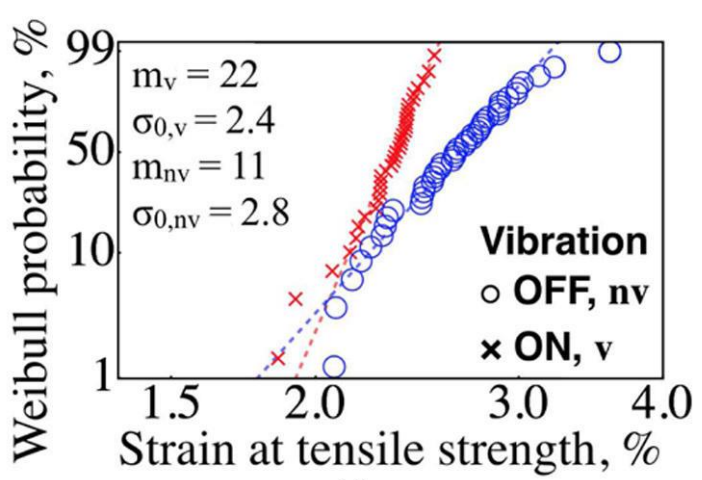

(d)

Figure 15. Linearized Weibull distribution for non-vibrated (blue circle) and vibrated (red x) FDMed SCFR-ABS. $m_{v}, \sigma_{0, v}, m_{n v}$, and $\sigma_{0, n v}$ are vibrated Weibull modulus, vibrated characteristic value, non-vibrated modulus, and non-vibrated characteristic value. a) Fracture stress; b) tensile strength; c) nominal strain at break; d) strain at tensile strength Adopted from O. Keles et. al. [38]. 


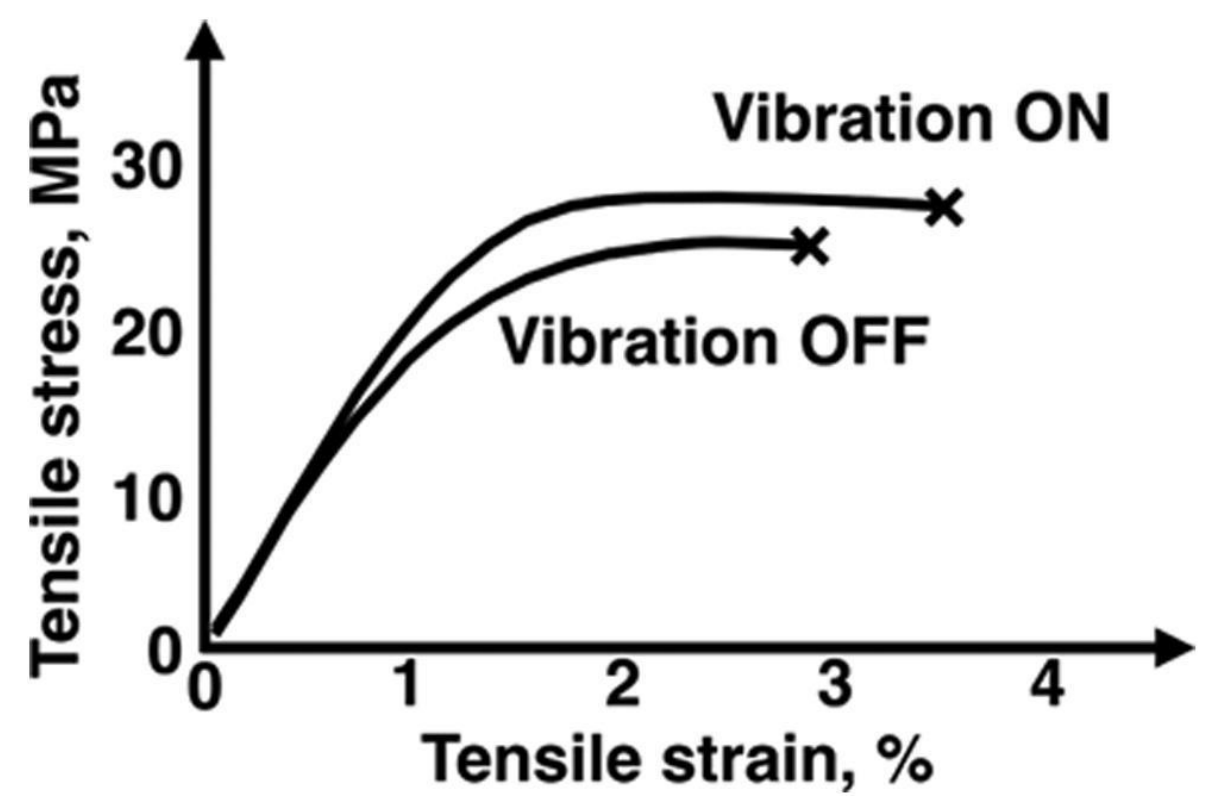

Figure 16. Stress-strain curves of the highest fracture stress of the vibrated and nonvibrated populations. Adopted from O. Keles et. al. [38].

Weibull analysis was used to quantify the variations in $\sigma_{f}, T S, e_{f}$ and strain at TS $\left(e_{T S}\right)$. The Weibull modulus showed an increase with vibrated for TS and $\sigma_{f}$ by $200 \%$. This means the variance in $\sigma_{f}$, TS and $e_{f}$ is much less than with the vibrated samples. Previous work with clean ABS showed a significantly higher modulus $(m=46)$ than the non-vibrated $(m=25)$. With vibrations, the modulus increased from 25 to 57 . This is higher than the previous $m=46$ clean ABS produced by the Stratasys uPrint SE. This suggest that a low-cost printer is capable of producing parts as, or more, reliable than the high-end Strasys system. Vibrations decreased the $e_{T S}$, showing that the maximum loadbearing capacity is reached at lower strain levels than non-vibrated. This means that the vibrated specimen has a more uniform microstructure than the non-vibrated.

Additionally, an Anderson-Darling goodness-of-fit test was used to determine whether 
the data represent a normal or Weibull distribution. There was no significant statistical difference between the Weibull and normal distributions.

An improved Weibull modulus means a more reliable material; low allowable-failurerate materials with low Weibull moduli are unusable. Therefore, any improvements to the Weibull modulus increases the possibility of FDMed for manufacturing applications.

The variation in mechanical properties is primarily determined by the size and morphology of the inter-bead pores. The consistency of the size and shape of these interbead pores is dependent on the accuracy of the printer. If the printer can lay beads at a consistent distance from each other, the inter-bead pores will be consistent. However, if the accuracy of the printer is low, then the bead-to-bead spacing will differ, varying the sizes and shapes of the inter-bead pores. Mechanical factors affecting accuracy include the extrusion-nozzle diameter, servo motors, and the belt system. There are also factors that contribute to the inter-bead pore size that are not native to the printer: filament homogeneity, variations in filament thickness, and G-code variations.

The mechanical properties of FDMed SCFR-ABS depend on inter-bead pores, innerbead pores, carbon fiber, crazing, and their interactions. Of these features, inter-bead pores have the largest effect on mechanical properties. This is due to the size and stress concentration they add to the system. This effect can be seen when comparing the fracture surfaces of vibrated and non-vibrated material (Figure 17). The non-vibrated specimen has a single crazing region (seen as cloudy white on the fracture surface), whereas the vibrated has two less-concentrated crazing regions. These multiple crazing regions indicate competing crack propagation. This shows that the reduced vibrated 
samples distribute the load more evenly through the sample than the large pores of the non-vibrated material.

Vibration OFF

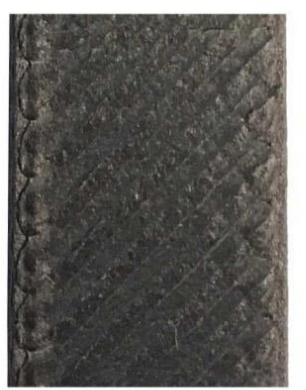

(a)
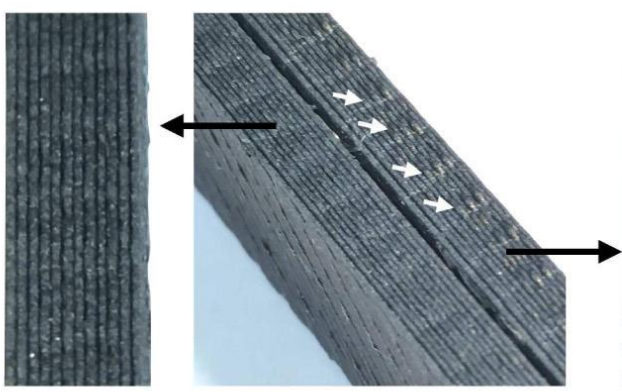

Vibration ON
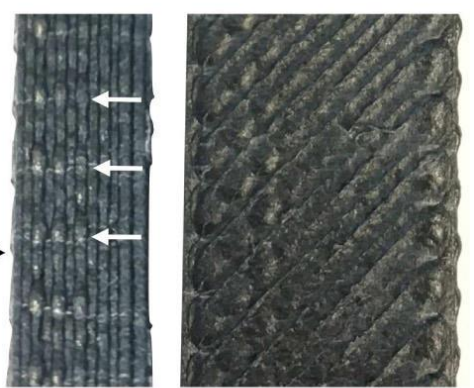

(b)

Figure 17. Photographs of the surface finish of the vibrated and non-vibrated tensile-test specimens. Adopted from O. Keles et. al. [38].

In both the vibrated and non-vibrated samples, the fracture originates from the interbead pores near the contour. The vibrated specimens narrow the distribution of pore sizes by eliminating elongated pores. With a narrow distribution of inter-bead pore sizes, the distribution of mechanical properties also becomes narrower.

One possible concern of adding a vibration to the print process is the effect on build resolution. To mitigate this, the perimeter, the top two layers, and the bottom two layers were not vibrated. A difference in surface roughness can be seen on the top and side surface of the part (Figure 17). This can be mitigated by more non-vibrated surface layers and more parameters. Generally, specimens were thicker and wider compared to those that were non-vibrated. The height was $3.88 \pm .05 \mathrm{~mm}$ average for non-vibrated and $3.93 \pm 0.1 \mathrm{~mm}$ average vibrated. The width was $13.2 \pm 0.1 \mathrm{~mm}$ average for nonvibrated and $13.3 \pm .2 \mathrm{~mm}$ average for vibrated. 
VA-FDM is a novel, cost-effective technique for reducing inter-bead porosity and therefore improving the mechanical properties of the SCFR-ABS. By attaching the vibrational motor to the fan's pulse-width modulated pins on the Arduino board, the vibrations can be turned on and off, and frequency can be adjusted at will. This gives the ability to preserve surface finish and optimize vibration frequency for different headtravel speeds and nozzle diameters. With the addition of vibrational motors in different axes and an ultrasonic transducer, the researchers believe that further reductions in porosity can be achieved. The researchers also believe that this technique can reduce the size and number of inner-bead pores, allowing for larger nozzle diameters and faster print with stronger materials.

\subsection{Conclusion}

The mechanical properties of FDMed composites are major barriers for widespread adoption in mass-production and mass-customization industries. The novel technique presented in this paper, VA-FDM, has been shown to decrease inter-bead porosity. Decreasing the inter-bead porosity increased fracture strength, tensile strength, nominal strain at break, and the elastic modulus of FDMed SCFR-ABS. The work of fracture also increased by $49 \%$. The variations in mechanical properties were decreased; in other words, the mechanical reliability of the material was increased. VA-FDM nearly doubled the Weibull moduli of $\sigma_{f}$ and TS. Further improvements on mechanical properties can be achieved by reducing infill to contour pores, increasing contour thickness, and using pore-free filaments. 


\section{CHAPTER EIGHT \\ CONCLUSION AND FUTURE WORK}

This paper aims to accomplish three goals: first, to provide reliability data for consumer-based FDMed ABS and SCFR-ABS; second, to investigate the causes of low mechanical proprieties; and finally, to address identified causes of mechanical variations and improve mechanical properties and reliability. A summary and future work will be discussed below.

\subsection{Reliability Data}

In this paper, the author reported the mechanical properties and reliability as a function of porosity in Tables 3 and 4, for neat ABS and SCFR-ABS, respectively. In addition to data that have been produced by this research group, there have not been sample sizes large enough to conduct adequate reliability studies for FDMed polymers and composites. Additive manufactured parts should be used for load-bearing applications to maintain commercial growth. Without reliability data, parts may be produced with improper processing parameters, risking property and human safety. The author believes that these data would best be utilized by slicing software. Designers would specify forces on their desired parts as well as acceptable failure rates; then, the software would suggest the infill percentage that would optimize performance, speed, and material usage.

There are many production parameters that could affect the reliability of FDMed materials. Nozzle diameter, extrusion temperature, and material selection are all parameters suggested to affect mechanical reliability, but these were out of the scope of this thesis. The only studies conducted in this work involved tensile forces. There are 
missing reliability data for other mechanical tests, including four-point bend tests, cycle testing, and high-strain studies. For a robust parameter-selecting, slicing software, these additional data sets would be beneficial.

\subsection{Investigating the Causes of High Variance}

The nominally dense material reported in this study was $15,13,23,10$, and 8 vol. $\%$ for SCFR-ABS M1, SCFR-ABS M2, SCFR-ABS M2 $0^{\circ}$, SCFR-ABS M2 vibrated and neat ABS, respectively (Table 5). These porous samples dominate the mechanical variability behavior. Pores in FDMed polymers and composites come in two varieties: inner-bead and inter-bead pores. In chapter 6.3, the author discussed the factors that may contribute to the production of inner- and inter-bead pores. Factors that contribute to inter-bead porosity include carbon-fiber content, printer positional accuracy, and nozzle diameter. Factors that contribute to inner-bead porosity are fiber-matrix mismatch, porosity in feedstock filament, and extrusion temperature.

Table 5 Porosity of Nominally Dense FDMed Material

\begin{tabular}{cc}
$\begin{array}{c}\text { Approximate } \\
\text { Vol. \% of Pores }\end{array}$ & Description \\
\hline 15 & SCFR-ABS M1 \\
13 & SCFR-ABS M2 \\
23 & SCFR-ABS M2 0 \\
10 & SCFR-ABS M2 \\
8 & vibrated \\
& neat ABS \\
\hline
\end{tabular}

With the vibrated-assisted FDM printing, the researchers were able to show that a reduction in porosity corresponds to a reduction in mechanical variability. However, the degree to which each pore type contributed to mechanical reliability is unknown. Future 
work could include testing the pore-generating parameters to examine their contribution to mechanical reliability. For example, the effect of extrusion temperature on inter- and inner-bead formation and mechanical reliability would be a useful study.

\subsection{Addressing Identified Causes of Mechanical Variability}

The inner- and inter-bead pores were identified in chapter six. To address these properties, vibrational-assisted FDM was developed in order to reduce these pores in hopes of increasing mechanical properties. The average porosity of the tensile specimen was 8 vol. \% compared to 13 vol. \% of the non-vibrated. This is evidence of a reduction of inner- and inter-bead pores. Fracture stress, tensile strength, and strain at fracture all increased by $10 \%$. The Weibull modulus for fracture stress increased $200 \%$. This suggests that there is a strong correlation between porosity and mechanical reliability.

The vibrational method reduced porosity but did not isolate between inter- and innerbead porosity. Future research would investigate the degree of pore reduction for both inter- and inner-bead reduction as well as of fiber orientations that would contribute to strengthening and improvement in reliability. Further improvements could be made to improve the mechanical properties of FDMed SCFR ABS. The improvements actively pursued by this group include multi-axis vibrations, feedback-vibration systems, and ultrasonic tip vibrations. In addition to this, other systems including clean ABS, lower infill percentages, and other FDM machines could further the understanding of this process. 


\section{REFERENCES}

1. I. Gibson, D.W. Rosen and B. Stucker, Additive Manufacturing Technologies (Springer. 2010), .

2. T. Wohlers, "Wohlers report 2013: Additive manufacturing and 3D printing state of the Industry-Annual worldwide progress report, wohlers associates, "Inc., Fort Collins, (2013).

3. B. Berman, "3-D printing: The new industrial revolution," Business Horizons, 55, 155-162 (2012).

4. V. Petrovic, J. Vicente Haro Gonzalez, O. Jorda Ferrando, J. Delgado Gordillo, J. Ramon Blasco Puchades and L. Portoles Grinan, "Additive layered manufacturing: Sectors of industrial application shown through case studies, " International Journal of Production Research, 49, 1061-1079 (2011).

5. J. Zuniga, D. Katsavelis, J. Peck, J. Stollberg, M. Petrykowski, A. Carson and C. Fernandez, "Cyborg beast: A low-cost 3d-printed prosthetic hand for children with upper-limb differences," BMC Research Notes, 8, 1 (2015).

6. J. Coykendall, M. Cotteleer, J. Holdowsky and M. Mahto, "3D opportunity in aerospace and defense: Additive manufacturing takes flight," A Deloitte Series on Additive Manufacturing, 1(2014).

7. Y. Song, Y. Yan, R. Zhang, D. Xu and F. Wang, "Manufacture of the die of an automobile deck part based on rapid prototyping and rapid tooling technology," Journal of Materials Processing Technology, 120, 237-242 (2002).

8. I. Campbell, D. Bourell and I. Gibson, "Additive manufacturing: Rapid prototyping comes of age," Rapid Prototyping Journal, 18, 255-258 (2012).

9. A. Gebhardt, F. Schmidt, J. Hötter, W. Sokalla and P. Sokalla, "Additive manufacturing by selective laser melting the realizer desktop machine and its application for the dental industry," Physics Procedia, 5, 543-549 (2010).

10. J.M. Pearce, "Materials science. building research equipment with free, opensource hardware," Science (New York, N.Y.), 337, 1303-1304 (2012).

11. B.T. Wittbrodt, A. Glover, J. Laureto, G. Anzalone, D. Oppliger, J. Irwin and J.M. Pearce, "Life-cycle economic analysis of distributed manufacturing with open-source 3-D printers, " Mechatronics, 23, 713-726 (2013). 
12. S. Lim, R.A. Buswell, T.T. Le, S.A. Austin, A.G. Gibb and T. Thorpe, "Developments in construction-scale additive manufacturing processes," Automation in Construction, 21, 262-268 (2012).

13. M. Perez, E. MacDonald, D. Espalin and R. Wicker, "3d Printing MultiFunctionality: Aerospace Structures with Electronics," Rapdasa 2014, 2014, .

14. F.E. Tay, M. Manna and L. Liu, "A CASD/CASM method for prosthetic socket fabrication using the FDM technology, " Rapid Prototyping Journal, 8, 258-262 (2002).

15. D. Bourell, B. Stucker, D. Espalin, K. Arcaute, D. Rodriguez, F. Medina, M. Posner and R. Wicker, "Fused deposition modeling of patient-specific polymethylmethacrylate implants, " Rapid Prototyping Journal, 16, 164-173 (2010).

16. D. Bourell, B. Stucker, R. Ilardo and C.B. Williams, "Design and manufacture of a formula SAE intake system using fused deposition modeling and fiber-reinforced composite materials, " Rapid Prototyping Journal, 16, 174-179 (2010).

17. C. Lee, C. Chua, C. Cheah, L. Tan and C. Feng, "Rapid investment casting: Direct and indirect approaches via fused deposition modelling," The International Journal of Advanced Manufacturing Technology, 23, 93-101 (2004).

18. O. Keles, C.W. Blevins and K.J. Bowman, "Effect of build orientation on the mechanical reliability of $3 D$ printed ABS, " Rapid Prototyping Journal, 23(2017).

19. H.L. Tekinalp, V. Kunc, G.M. Velez-Garcia, C.E. Duty, L.J. Love, A.K. Naskar, C.A. Blue and S. Ozcan, "Highly oriented carbon fiber-polymer composites via additive manufacturing," Composites Science and Technology, 105, 144-150 (2014).

20. L. Baich and G. Manogharan, "Study of infill print parameters on mechanical strength and production cost-time of $3 d$ printed abs parts," .

21. C.M. Haid, Characterizing Tensile Loading Responses of 3D Printed Samples, (2014).

22. B.N. Panda, M. Leite, A. Carvalho and B.B. Biswal, "Compressive property characterization of FDM printed cellular structures," .

23. O. Lužanin, D. Movrin and M. Plančak, "Effect of layer thickness, deposition angle, and infill on maximum flexural force in FDM-built specimens, " Journal for Technology of Plasticity, 39(2014). 
24. M. Fernandez-Vicente, W. Calle, S. Ferrandiz and A. Conejero, "Effect of infill parameters on tensile mechanical behavior in desktop 3D printing, "3D Printing and Additive Manufacturing, 3, 183-192 (2016).

25. V. Vega, J. Clements, T. Lam, A. Abad, B. Fritz, N. Ula and O.S. Es-Said, "The effect of layer orientation on the mechanical properties and microstructure of a polymer, "Journal of Materials Engineering and Performance, 20, 978-988 (2011).

26. Y. Shanjani, Y. Hu, R.M. Pilliar and E. Toyserkani, "Mechanical characteristics of solid-freeform-fabricated porous calcium polyphosphate structures with oriented stacked layers," Acta Biomaterialia, 7, 1788-1796 (2011).

27. T. Huang, M.S. Mason, X. Zhao, G.E. Hilmas and M.C. Leu, "Aqueous-based freeze-form extrusion fabrication of alumina components, " Rapid Prototyping Journal, 15, 88-95 (2009).

28. S. Iyer, J. McIntosh, A. Bandyopadhyay, N. Langrana, A. Safari, S. Danforth, R. Clancy, C. Gasdaska and P. Whalen, "Microstructural characterization and mechanical properties of Si3N4 formed by fused deposition of ceramics," International Journal of Applied Ceramic Technology, 5, 127-137 (2008).

29. Ö. Keleș, C. W. Blevins, K. J. Bowman, "Effect of build orientation on the mechanical reliability of $3 D$ printed ABS, " Rapid Prototyping Journal, $\operatorname{Accepted}(2016)$.

30. S.T. Ho and D.W. Hutmacher, "A comparison of micro CT with other techniques used in the characterization of scaffolds," Biomaterials, 27, 1362-1376 (2006).

31. T. Schlordt, S. Schwanke, F. Keppner, T. Fey, N. Travitzky and P. Greil, "Robocasting of alumina hollow filament lattice structures," Journal of the European Ceramic Society, 33, 3243-3248 (2013).

32. U. Saeed and G. Rizvi, "Three-dimensional orientation of compression-molded high-density polyethylene/wood fibers using X-ray micro-tomography," Journal of Cellular Plastics, 51, 45-57 (2015).

33. Z. Quan, Z. Larimore, X. Qin, J. Yu, M. Mirotznik, J. Byun, Y. Oh and T. Chou, "Microstructural characterization of additively manufactured multi-directional preforms and composites via X-ray micro-computed tomography," Composites Science and Technology, 131, 48-60 (2016).

34. T. Hofstätter, I.W. Gutmann, T. Koch, D.B. Pedersen, G. Tosello, G. Heinz and H.N. Hansen, "Distribution and Orientation of Carbon Fibers in Polylactic Acid 
Parts Produced by Fused Deposition Modeling," Proceedings of Aspe Summer Topical Meeting 2016, 2016, .

35. M. Feser, J. Gelb, H. Chang, H. Cui, F. Duewer, S. Lau, A. Tkachuk and W. Yun, "Sub-micron resolution CT for failure analysis and process development,"

Measurement Science and Technology, 19, 094001 (2008).

36. A.P. Merkle and J. Gelb, "The ascent of $3 D$ X-ray microscopy in the laboratory," Microscopy Today, 21, 10-15 (2013).

37. Ö Keleş, E.H. Anderson, J. Huynh, J. Gelb, J. Freund and A. Karakoç, "Stochastic fracture of additively manufactured porous composites, " Scientific Reports, 8, 15437 (2018).

38. Ö Keleş, E.H. Anderson and J. Huynh, "Mechanical reliability of short carbon fiber reinforced ABS produced via vibration assisted fused deposition modeling," Rapid Prototyping Journal, (2018).

39. J. Li and C. Cai, "The carbon fiber surface treatment and addition of PA6 on tensile properties of ABS composites, " Current Applied Physics, 11, 50-54 (2011).

40. J. Li, "Interfacial studies on the $O 3$ modified carbon fiber-reinforced polyamide 6 composites," Applied Surface Science, 255, 2822-2824 (2008).

41. F. Rezaei, R. Yunus and N. Ibrahim, "Effect of fiber length on thermomechanical properties of short carbon fiber reinforced polypropylene composites, " Materials \& Design, 30, 260-263 (2009).

42. G. Yan, X. Wang and D. Wu, "Development of lightweight thermoplastic composites based on polycarbonate/acrylonitrile-butadiene-styrene copolymer alloys and recycled carbon fiber: Preparation, morphology, and properties, " Journal of Applied Polymer Science, 129, 3502-3511 (2013).

43. L. English, "Higher performance from long-fiber thermoplastics, " Materials Engineering, 106, 35-38 (1989).

44. W. Chiang and K. Cheng, "Processing conditions for electromagnetic interference shielding effectiveness and mechanical properties of acrylonitrile-butadiene-styrene based composites, " Polymer Composites, 18, 748-756 (1997).

45. M. Montero, S. Roundy, D. Odell, S. Ahn and P.K. Wright, "Material characterization of fused deposition modeling (FDM) ABS by designed experiments," Society of Manufacturing Engineers, 10(2001). 
46. R.S. Bay and C.L. Tucker III, "Stereological measurement and error estimates for three-dimensional fiber orientation," Polymer Engineering \& Science, 32, 240-253 (1992).

47. A.K. Sood, R.K. Ohdar and S.S. Mahapatra, "Parametric appraisal of mechanical property of fused deposition modelling processed parts," Materials \& Design, 31, 287-295 (2010).

48. S. Ahn, M. Montero, D. Odell, S. Roundy and P.K. Wright, "Anisotropic material properties of fused deposition modeling ABS, " Rapid Prototyping Journal, 8, 248257 (2002).

49. W. Weibull, "Wide applicability, " Journal of Applied Mechanics, 103, 293-297 (1951).

50. S. Meininger, S. Mandal, A. Kumar, J. Groll, B. Basu and U. Gbureck, "Strength reliability and in vitro degradation of three-dimensional powder printed strontiumsubstituted magnesium phosphate scaffolds, "Acta Biomaterialia, 31, 401-411 (2016).

51. F. Ning, W. Cong, J. Wei, S. Wang and M. Zhang, "Additive Manufacturing of CFRP Composites using Fused Deposition Modeling: Effects of Carbon Fiber Content and Length," ASME 2015 International Manufacturing Science and Engineering Conference, 2015, pp. V001T02A067-V001T02A067.

52. F. Ning, W. Cong, Z. Hu and K. Huang, "Additive manufacturing of thermoplastic matrix composites using fused deposition modeling: A comparison of two reinforcements, " Journal of Composite Materials, , 0021998317692659 (2017).

53. L.J. Love, V. Kunc, O. Rios, C.E. Duty, A.M. Elliott, B.K. Post, R.J. Smith and C.A. Blue, "The importance of carbon fiber to polymer additive manufacturing," Journal of Materials Research, 29, 1893-1898 (2014).

54. F. Ning, W. Cong, J. Qiu, J. Wei and S. Wang, "Additive manufacturing of carbon fiber reinforced thermoplastic composites using fused deposition modeling," Composites Part B: Engineering, 80, 369-378 (2015).

55. M. Shofner, K. Lozano, F. Rodríguez-Macías and E. Barrera, "Nanofiberreinforced polymers prepared by fused deposition modeling, " Journal of Applied Polymer Science, 89, 3081-3090 (2003).

56. G.W. Melenka, B.K. Cheung, J.S. Schofield, M.R. Dawson and J.P. Carey, "Evaluation and prediction of the tensile properties of continuous fiber-reinforced 3 D printed structures," Composite Structures, 153, 866-875 (2016). 
57. R. Matsuzaki, M. Ueda, M. Namiki, T. Jeong, H. Asahara, K. Horiguchi, T. Nakamura, A. Todoroki and Y. Hirano, "Three-dimensional printing of continuousfiber composites by in-nozzle impregnation," Scientific Reports, 6, 23058 (2016).

58. S. Dul, L. Fambri and A. Pegoretti, "Fused deposition modelling with ABSgraphene nanocomposites," Composites Part A: Applied Science and Manufacturing, 85, 181-191 (2016).

59. Y. Xu, L. Cheng, L. Zhang, D. Yan and C. You, "Optimization of sample number for weibull function of brittle materials strength," Ceramics International, 27, 239241 (2001).

60. C.T. Rueden, J. Schindelin, M.C. Hiner, B.E. DeZonia, A.E. Walter, E.T. Arena and K.W. Eliceiri, "ImageJ2: ImageJ for the next generation of scientific image data," BMC Bioinformatics, 18, 529 (2017).

61. S.R. Stock, Microcomputed Tomography: Methodology and Applications (CRC press. 2008), .

62. D. Qiu and N.A. Langrana, "Void eliminating toolpath for extrusion-based multimaterial layered manufacturing," Rapid Prototyping Journal, 8, 38-45 (2002).

63. J. Wang, H. Xie, Z. Weng, T. Senthil and L. Wu, "A novel approach to improve mechanical properties of parts fabricated by fused deposition modeling," Materials \& Design, 105, 152-159 (2016).

64. E. Ryshkewitch, "Compression strength of porous sintered alumina and zirconia," Journal of the American Ceramic Society, 36, 65-68 (1953).

65. W. Duckworth, "Discussion of ryshkewitch paper, "Journal of the American Ceramic Society, 36, 68 (1953).

66. Ö Keleș, R. Edwin García and K.J. Bowman, "Sensitivity of fracture strength in porous glass," International Journal of Applied Glass Science, 8, 116-123 (2017).

67. F. Ning, W. Cong, Y. Hu and H. Wang, "Additive manufacturing of carbon fiberreinforced plastic composites using fused deposition modeling: Effects of process parameters on tensile properties, "Journal of Composite Materials, 51, 451-462 (2017).

68. T. Ohsawa, A. Nakayama, M. Miwa and A. Hasegawa, "Temperature dependence of critical fiber length for glass fiber-reinforced thermosetting resins, "Journal of Applied Polymer Science, 22, 3203-3212 (1978). 
69. M. Miwa and I. Endo, "Critical fibre length and tensile strength for carbon fibreepoxy composites," Journal of Materials Science, 29, 1174-1178 (1994).

70. J.P. Lewicki, J.N. Rodriguez, C. Zhu, M.A. Worsley, A.S. Wu, Y. Kanarska, J.D. Horn, E.B. Duoss, J.M. Ortega and W. Elmer, "3D-printing of meso-structurally ordered carbon fiber/polymer composites with unprecedented orthotropic physical properties," Scientific Reports, 7, 43401 (2017).

71. T.H. Courtney, Mechanical Behavior of Materials (Waveland Press. 2005), .

72. Ö Keleş, R.E. García and K.J. Bowman, "Stochastic failure of isotropic, brittle materials with uniform porosity," Acta Materialia, 61, 2853-2862 (2013).

73. A. Mohamed, S. Maidin, S. Mohamed, M. Muhamad, J. Wong and W. Romlee, "Improvement of surface finish by multiple piezoelectric transducers in fused deposition modelling," International Journal on Advanced Science, Engineering and Information Technology, 6, 764-769 (2016). 